Portland State University

PDXScholar

Spring 1-1-2012

\title{
Understanding Sand Mining on the Maha Oya: The Conflict Between Economic and Environmental Survival
}

Meredith Corea Talbert

Portland State University

Follow this and additional works at: https://pdxscholar.library.pdx.edu/open_access_etds

Part of the Natural Resource Economics Commons, Place and Environment Commons, and the Regional Sociology Commons

Let us know how access to this document benefits you.

\section{Recommended Citation}

Talbert, Meredith Corea, "Understanding Sand Mining on the Maha Oya: The Conflict Between Economic and Environmental Survival" (2012). Dissertations and Theses. Paper 522.

https://doi.org/10.15760/etd.522

This Thesis is brought to you for free and open access. It has been accepted for inclusion in Dissertations and Theses by an authorized administrator of PDXScholar. Please contact us if we can make this document more accessible: pdxscholar@pdx.edu. 
Understanding Sand Mining on the Maha Oya:

The Conflict Between Economic and Environmental Survival

by

Meredith Corea Talbert

A thesis submitted in partial fulfillment of the requirements for the degree of

Master of Science

in

Sociology

Thesis Committee:

Margaret Everett, Chair

Veronica Dujon

Alex Stepick

Portland State University

(C)2012 


\begin{abstract}
River sand mining from the Maha Oya is the main source of income and a force that drives economic activity for residents along the river. This study takes place in Sri Lanka, there are three villages included in this project: Jambugaswatte, Janituspuraya and Thoppuwa. In Sri Lanka, sand serves as the main building material. It is used to make bricks, tiles, asphalt and concrete, therefore demanding a high market value. However, the over-extraction of sand comes along with significant environmental problems. These communities depend on the river in many ways and the health of the river directly corresponds to the health of the ecosystem as a whole. Along the Maha Oya two important elements of survival are in conflict with one another: residents simultaneously need a healthy, thriving ecosystem to live in, as well as economic opportunities.

With support from the Environmental Foundation Ltd. (EFL)—a Sri Lankan environmental justice NGO — this study focuses on the complex situation with sand mining on the Maha Oya. Data for this study comes from fifteen formal interviews with a Sinhala-English translator. These interviews are used to address the two research questions for this project: how do village residents along the Maha Oya perceive sand mining? And what are the emotional, practical and theoretical responses of village residents to the effects of sand mining on their local ecosystems? In order to envision a sustainable future, it is vital to begin with a clear understanding of community perceptions of these complex issues, which are at the heart of this project.
\end{abstract}




\section{Acknowledgements}

First of all, I want to thank all the people who participated in this project; each one of you who let me into your home and treated me with immense kindness. Likewise, this project could not have been done without the support of EFL and staff, with a very special thanks to Priyanka Mudalige. I would also like to thank my thesis committee Veronica Dujon, Alex Stepick, and especially my chair Margaret Everette, who was always available to offer me guidance and encouragement.

I want to acknowledge my amazing family, my parents Michael and Christine, my brother Andrew and sister Kate. You have all given me unending love and support throughout this journey. Finally, I want to thank the wonderful students of my cohort. The support and community we formed over coffee, work sessions and brainstorming has been invaluable in my graduate experience. And a very special thanks to my dear friend, research accomplice, and Sri Lankan traveling buddy, Katy Griffin. 
Table of Contents

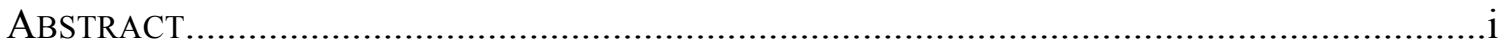

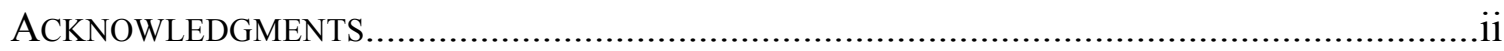

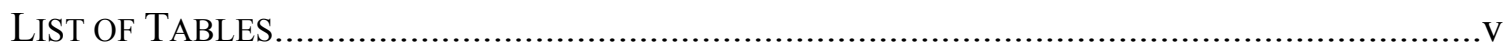

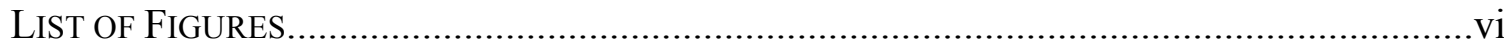

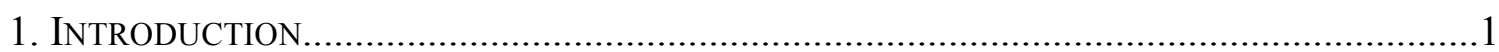

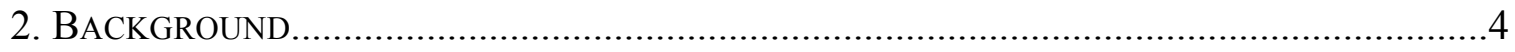

River Sand Mining in Sri Lanka..........................................................

Detrimental Effects of River Sand Mining............................................8

Environmental Foundation Ltd.......................................................11

Applied Sociology at EFL...........................................................16

3. LITERATURE REVIEW \& THEORETICAL FRAMEWORK...............................................

Environmental Sociology................................................................19

Challenging the Tragedy of the Commons Ideology.............................25

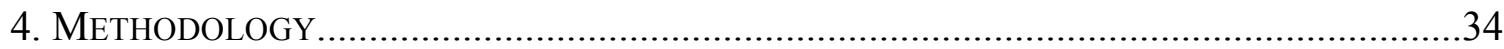

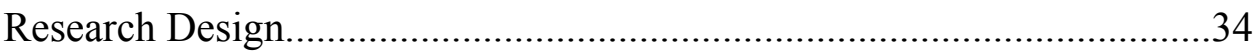

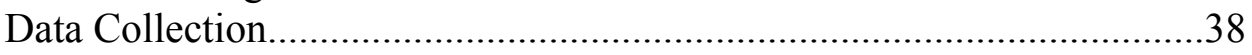

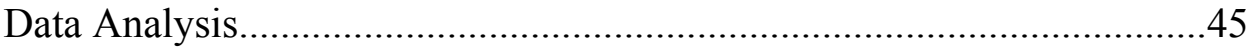

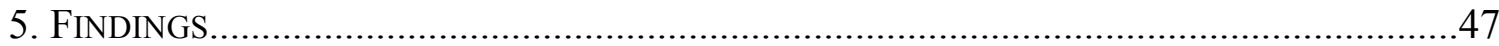

General Opinions about Sand Mining....................................................47

Connecting Sand Mining and the Environment.....................................49

Communication about Sand Mining in the Community..........................54

Economic Dependence on Sand Mining ...............................................58

Legal Concerns with Sand Mining..................................................62

Social Problems Associated with Sand Mining....................................63

Water Related Issues.......................................................................64

Support for the Continuation of Sand Mining......................................66

Gender and the Environment..........................................................67

6. PARTICIPANT OBSERVATION FindingS...............................................................69

Mangroves for the Future Committee Visit the Maha Oya......................70

Shoe Making as an Alternative Livelihood............................................74

Environmental and Social Effects of Sand Mining on the Coastline.........77

Collecting Water Data on the Maha Oya...............................................79

A Space to Talk about Sand Mining.......................................................8 80

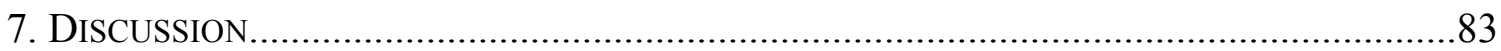

The Paradox on the Maha Oya.............................................................83

Communities and Conservation..........................................................85

iii 
How do Village Residents Understand their Environment......................86

Does the Tragedy of the Commons Apply?............................................88

Application of this Study to the Greater Project.....................................90

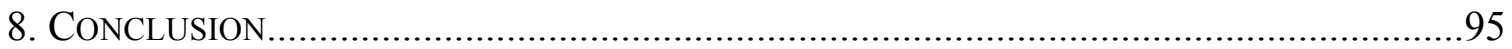

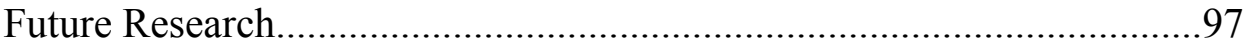

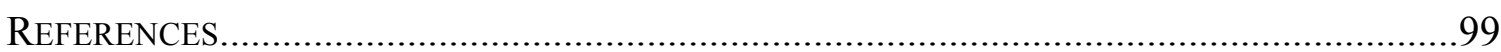

APPENDIX

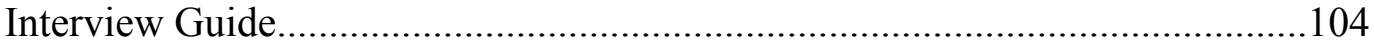




\section{List of Tables}

\section{TABLE 1}

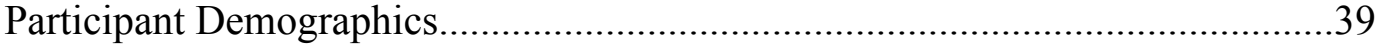

TABLE 2

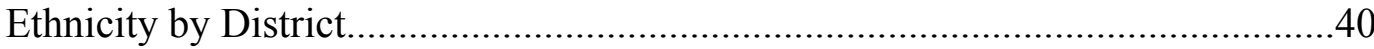




\section{List of Figures}

FIGURE 1

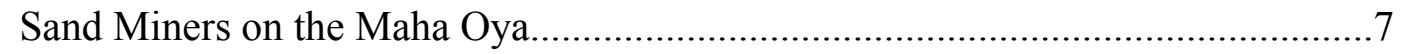

FIGURE 2

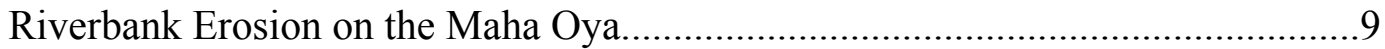

FIGURE 3

Map of Thoppuwa, Janituspurya and Jambugaswatte.......................................13

FIGURE 4

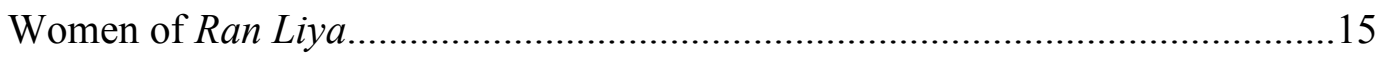

FIGURE 5

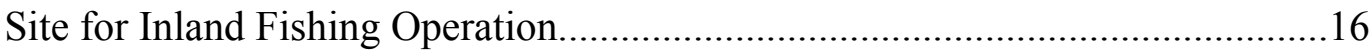

FiguRE 6

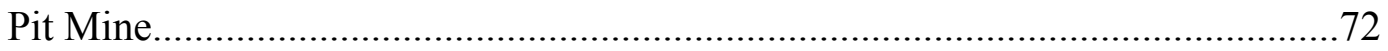

FIGURE 7

Shoe Making Training \& Shoes.................................................................. 75

FIGURE 8

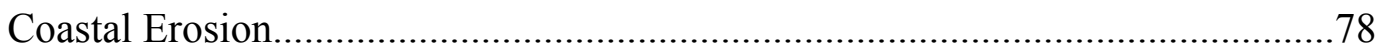




\section{CHAPTER 1: INTRODUCTION}

For the communities of Jambugaswatte, Janituspuraya, and Thoppuwa sand mining is at the center of daily life. These three villages are situated along the Maha Oya - one of the largest rivers in Sri Lanka — in the Western part of the island. Sand serves as the foundation for most construction done in Sri Lanka, and a great deal of the necessary sand comes from the riverbed of the Maha Oya. Given the necessity of sand for building, it commands a high market value, making sand mining a lucrative business. The problem, however, is that the over extraction of sand from the Maha Oya comes along with a whole host of environmental consequences.

For most people, the process and concept of sand mining is totally foreign, so it is important to first understand what is happening. Sand mining in Sri Lanka is done in two main ways, either mechanically or traditionally. Mechanical methods necessitate the use of large machinery. The outcome of this process is drastic alterations to entire ecosystems. On the other hand, traditional methods involve individuals diving to the bottom of the river and pulling each bucket of sand to the surface by hand, a labor intensive and tiresome process. Both methods will be described further in more detail.

The residents of the villages along the Maha Oya depend wholly on the river in a multitude of ways. The health of the river directly corresponds to the health of the ecosystem as a whole; therefore its protection is vital. Although, the economic opportunity of sand mining makes this a complex situation, for many families it is the only means of providing food for their families. Along the Maha Oya two important elements of survival are in direct conflict with one another, on the one hand the need for a thriving ecosystem, and on the other the need for economic survival. 


\section{The ENVIRONMENTAL Foundation LTD.}

The various issues involved in sand mining in Sri Lanka have gained attention from local and international environmentally focused groups alike. One of them is the Environmental Foundation Ltd. (EFL) a Sri Lankan based non-governmental organization. Employing the skills of environmental scientists and lawyers, EFL is dedicated to achieving environmental justice in Sri Lanka. In the summer of 2009 staff at EFL began working on a project to introduce alternative livelihoods in several villages along the Maha Oya where sand mining has been especially detrimental. The goal is to provide support to those who wish to separate themselves from the sand mining industry while still having the means to feed their families. By providing education about the problems associated with sand mining the intention is to limit the destruction of the river.

I spent three months working as an intern for EFL; during this time I was able to see first-hand how the issues surrounding sand mining are being addressed. Likewise, I was able to apply a sociological perspective to the current situation of the communities along the Maha Oya. The outcome was to gain a comprehensive look at how village residents are dealing with sand mining; this type of inquiry is useful to effectively guide and support the overall EFL project.

\section{RESEARCH DESIGN}

In order to address the multifaceted situation on the Maha Oya, it is important to begin with a full perspective on how residents use and understand their environment. This thesis project aims at just that through the use of in-depth interviews with village residents. These are important issues for environmental sociologists to tackle because it 
speaks to the imbalance and tension between two conflicting values and modes of survival.

There are two main questions, which will be addressed within this thesis. 1. How do village residents along the Maha Oya perceive sand mining? By this question the ultimate goal is to be able to describe how the communities immersed in this industry tend to understand sand mining, and 2. What are the emotional, practical and theoretical responses of village residents to the effects of sand mining on their local ecosystems? In this question I will be exploring how people along the Maha Oya are dealing with or understanding the consequences of the over-exploitation of sand. 


\section{CHAPTER 2: BACKGROUND}

This thesis project is rooted in the sand mining industry along the Maha Oya. The many communities who depend on the river for survival in one way or another are affected daily by actions both for and against the continuation of sand mining. In much of the westernized world, however, the idea and process of sand mining is entirely foreign. The following chapter aims to create a picture of issues surrounding sand mining particular to the villages included in this study. Included is an explanation of sand mining, its various methods and effects on the environment, a portrayal of the Environmental Foundation Ltd, a description of their project and my role within the organization as an intern.

\section{River SANd Mining in SRI LANKa}

In Sri Lanka there is a considerable need for sand, which has led to the overexploitation of this particular resource from the nation's rivers. Sand is the major component of cinder blocks and cement, which are crucial to the construction industry. Sand is also required for necessary infrastructure projects like building roads and bridges (Gunaratne and Jayasooriya n.d.). In December of 2004 the Pacific tsunami caused a great deal of destruction in Sri Lanka, greatly increasing the need for sand due to rebuilding efforts.

River sand mining in Sri Lanka has proven to have many adverse effects. In response to concerns, the Mines and Minerals Act of 1992, in conjunction with the Geological Survey and Mines Bureau (GSMB), was put in place to oversee the regulation and licensing of river sand mining (Kamaladasa 2008). Because of the particular detrimental effects that some communities have faced, mining of river sand was banned 
completely on some rivers in Sri Lanka (Sri Lanka Water Partnership n.d.). Despite the GSMB's intentions to limit the amount of sand mined from the rivers, centralized oversight has actually created more problems than it solved (Sri Lanka Water Partnership n.d.). Since the government has limited resources, they are unable to monitor sand extraction from the Maha Oya; the river is at the center of these communities, essentially making it an open-access resource.

Although there is little enforcement of the laws limiting sand mining on the Maha Oya, in the cases were people are caught it is the men actually mining sand who get in trouble. It is these same men who are least likely to be in a position to choose an alternative livelihood. Those who own the necessary resources for extraction, earning a higher income, are not the ones getting caught. However, it is the resource owners who are in a better position to be able to make their living in another way.

For many people, sand mining represents an economic opportunity in the face of few alternatives (Gunaratne and Jayasooriya n.d.). The limited legal availability of sand — due to the Mines and Minerals Act of 1992 — combined with the increase in demand after the 2004 tsunami, made sand mining even more profitable. Decreasing supply and increasing demand led to a rise in the value of sand, presenting a lucrative economic opportunity, particularly for young men (Sri Lanka Water Partnership n.d.). In 2006 Sri Lanka demanded about eight million cubic meters of sand, a number which is expected to increase over the next few years; all of this demand is taken from the rivers of Sri Lanka (Jayawardena and Dissanayake 2006).

River sand is recognized as the most appropriate resource for building materials because individual grains tend to be evenly and consistently distributed (Jayawardena and 
Dissanayake 2006). Due to growing environmental concerns and increased government oversight of river sand mining there has been some recent dedication to finding a reliable substitute for river sand. Jayawardena and Dissanayake (2006) identify four possible alternatives to river sand for construction: dune sand, sea sand, manufactured sand and quarry dust. There are, however, problems associated with each of these other options. For example, it is very expensive to dredge the ocean and clean sea sand; additionally, the environmental consequences of this are at present, still unknown. Quarry dust is being explored as an option, but it is less preferable because it is not as uniform as river sand; also the viability of it depends greatly on the make-up of the parent rock (Jayawardena and Dissanayake 2006).

In general, there are two methods of sand mining, mechanized and traditional. Mechanized sand mining utilizes large machinery, such as backhoes and dump trucks, which can quickly alter ecosystems. The GSMB outlawed all mechanized sand mining, but this has not prevented it from being practiced illegally along the Maha Oya (Athukorala and Navaratne 2008).

Throughout Sri Lanka, traditional sand mining is still allowed, for those who hold the proper permits, in specified areas and on designated days of the week. Traditional (or artisan) sand mining dictates that no machinery is used (Geological Survey and Mines Bureau 2010). Because reliable explanations of the processes employed for sand mining do not exist, the following description is based on my observations and conversations with people in the field. Traditional mining is usually done in teams of about four men who take an un-motorized boat out on the river. Two men stay on the boat while the other two men dive to the bottom of the river, depths reaching up to thirty feet. Each diver fills 
a bucket with sand; the men on the boat then pull the buckets up while the divers return for air. This process is continued until the boat is filled with sand. Figure 1 shows two sand miners on the Maha Oya.

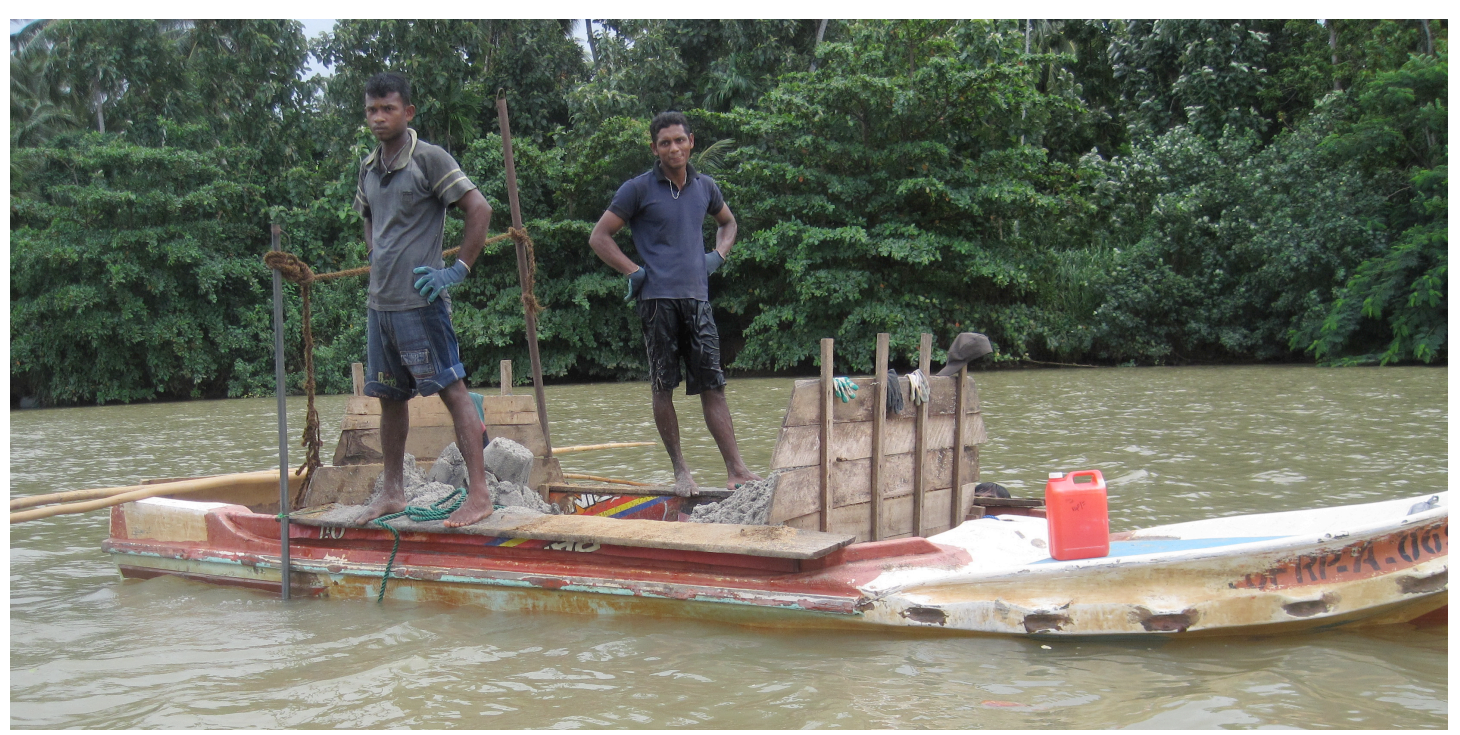

\section{Figure 1: Sand Miners on the Maha Oya}

Due to the fact that there are no published resources explaining the structure of the sand mining industry, this explanation comes from conversations with community members and observations while in the villages. There are a variety of roles people may take on within the sand mining industry, some of them more directly connected to harvesting than others. As far as I can tell, there are five main occupations: resource owners, sand miners, laborers, buyers and brick and tile factory workers. Resource owners are those who own the means of production such as boats and trucks, or heavy machinery in the case of mechanical sand mining. Sand miners are usually thought of as those who actually extract sand from the river, either using traditional or mechanical methods. Laborers are those who may be involved aspects such as loading and unloading 
sand after it is harvested. The buyers include those who purchase sand from the miners and resource owners. Since a great deal of sand goes to the brick and tile factories it is reasonable to consider the connection of these workers to the sand mining industry as well. Another important aspect to take into account is the connection of people who work in construction; although they are not directly involved in sand mining they are affected by fluctuations in availability and cost.

\section{Detrimental Effects Of River SANd Mining}

The overexploitation of river sand is significant for environmental, economic and social reasons that are all inherently connected. Sand mining causes drastic physical changes to the environment, and extensive environmental degradation; however, it has many other consequences as well. As rivers are altered, it affects the economic and social sustainability of the communities who depend on them. Ecological problems arise when sand is extracted faster than natural rates of replenishment, as is the current situation in Sri Lanka (Padmalal et al. 2008).

\section{ENVIRONMENTAL}

Primarily, river sand mining results in erosion and lowering of the water table. As sand is removed from the river the stability of the bank is compromised causing erosion, especially during flood season when the river is high (Padmalal et al. 2008). Figure 2 shows two examples of erosion along the banks of the Maha Oya. Over-extraction leads to a lack of sediment carried in the water, causing "undernourishment" of coastal beaches, and significant coastal erosion (Kondolf 1997). When the riverbed is heavily mined it causes the water table to fall, and the river to become deeper and more dangerous. In some cases, the water table has fallen so low that wells must be dug deeper 
to reach the water. Another consequence of sand mining is the intrusion of salt water, which is damaging to drinking water and soil alike (Gunaratne and Jayasooriya n.d.; Kamaladasa 2008).
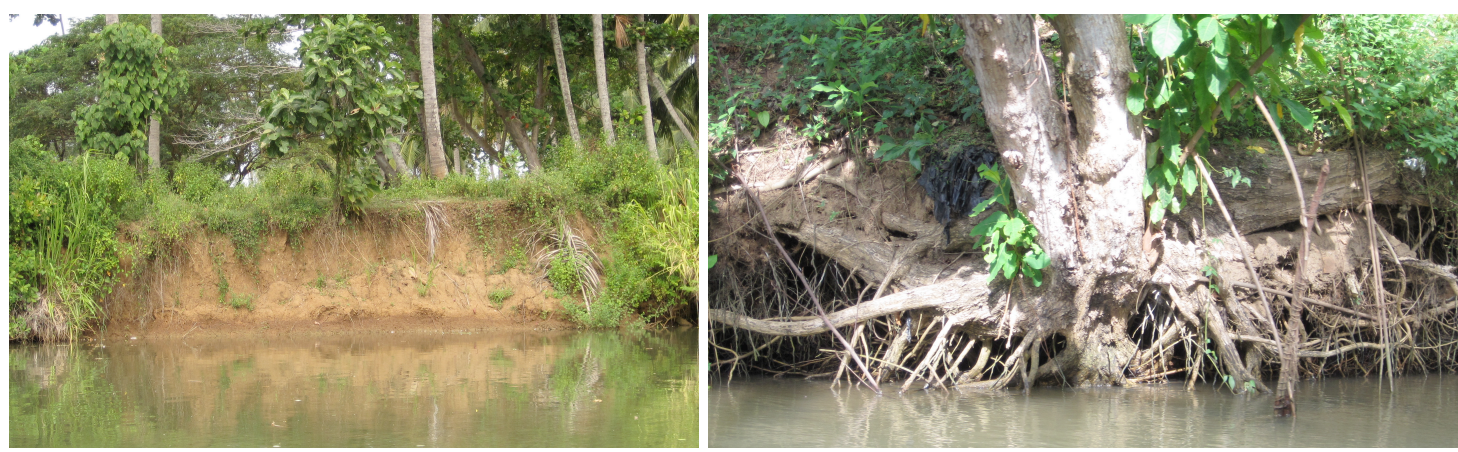

Figure 2: Riverbank Erosion on the Maha Oya

Sand mining in rivers causes damage to vegetation and loss of aquatic habitats (Gunaratne and Jayasooriya n.d.). Larger trees along riverbanks become unstable and fall, challenging the biodiversity of these fragile ecosystems (Kamaladasa 2008). In order to protect against the detrimental effects of drought and flood, Steenbergen and Tuinho (2009) suggest that it is imperative to find alternatives to river sand mining.

Along the specific 8-kilometer (4.97 miles) stretch of the Maha Oya, within the project area, there are a number of large pit mines that are of great concern. These large mined areas have created lakes along the river where land used to be. When pit mines are dug from the river's edge they result in swampy expanses where standing water increases the prevalence of mosquitoes and vector born diseases, as well as a loss of productive land.

ECONOMIC

In Sri Lanka many people depend on their land for their livelihoods. Therefore, when land is compromised it negatively affects the lives of families. Mining of river sand 
causes soil to become increasingly saline, making it less productive for growing crops (Gunaratne and Jayasooriya n.d.; Sri Lanka Water Partnership n.d.). Also, as riverbeds are eroded and pit mines are excavated, land is lost (Kamaladasa 2008). Coconut trees are an important resource in Sri Lankan society, though they are known for their weak roots, making them particularly susceptible to toppling because of erosion.

Another aspect of economic concern is the destruction of vital infrastructure; repair and rebuilding puts economic strain on communities and the government. For example, a number of bridges and power lines in Sri Lanka are unstable and face damage because the ground is not solid enough to support the weight (Kamaladasa 2008). Roadways and homes along rivers and coastal regions are threatened by similar destruction.

SOCIAL

The environmental and economic problems associated with sand mining also put the social health of communities at risk; river sand mining presents particular problems for health. As noted before, pit mines create breeding grounds for mosquitoes; mosquitoes are known to carry a number of diseases, such as dengue fever, straining the health care system (Gunaratne and Jayasooriya n.d.). Also, as is pointed out by the Sri Lanka Water Partnership, there are specific health risks for sand miners-for example, hearing loss, spinal injuries, and ear infections (Sri Lanka Water Partnership n.d.). The health problems that sand miners face means a greater draw on the communities' health services, and leads to a less healthy population.

The quality of drinking water poses significant health concerns; mining causes contamination of the water supply because of the intrusion of salt water (Kamaladasa 
2008). Rivers outside Colombo (the capital city) are the main sources of drinking water for the city. Water intake points for supplying the city's water are situated in strategic places to ensure flow. However, due to erosion caused by sand mining, water intake points that had been ideal in the past are no longer suitable (Kamaladasa 2008). Women are particularly impacted when there is not enough water for domestic use, as the burden of providing water traditionally falls to them (Sri Lanka Water Partnership n.d.).

After exploring these diverse problems, it is difficult to justify river sand mining in any capacity. However, it is important to understand the full spectrum of issues associated with sand mining. For people with few other economic opportunities the income from sand mining is crucial. According to the Sri Lanka Water Partnership (n.d.), the same populations that are negatively effected by sand mining are also the ones who stand to earn the most by illegally mining sand. This means that many Sri Lankans are hesitant to adhere to the ban and licensing system because their immediate need for income encourages them to continue the practice. Gunaratne and Jayasooriya (n.d.) advocate for sand miners and other beneficiaries to be included in a cooperative process of finding alternatives. The loss of sand mining as an income source will have a substantial effect on communities; this must be taken into consideration.

\section{ENVIRONMENTAL FOUNDATION LTD.}

Since 1981, the Environmental Foundation Ltd. (EFL) has been taking a stand against environmental degradation in Sri Lanka. EFL is a non-profit, non-governmental organization (NGO), whose goal is to keep the government accountable for the proper enforcement of Sri Lanka's existing environmental laws. Utilizing the expertise of environmental scientists and lawyers they seek "justice for nature" in Sri Lanka. The 
mission of EFL is "the conservation and enhancement of the natural environment through legal means" (Environmental Foundation Ltd. 2006).

During the summer of 2010-from June to August-I worked as an intern for EFL. Every year, EFL takes on several interns who are interested in supporting the mission of the organization in various ways. Through communication with staff members before I went to Sri Lanka they agreed that my skills and interests would be a good addition to their Maha Oya project. The Maha Oya project is a multi-dimensional project dedicated to increasing the sustainability of communities along the Maha Oya (river); this project will be described in more detail in the following section.

At EFL my main task was to conduct interviews, which would offer a better understanding of the perspectives and opinions of those living along the river. Since this is an applied research project, the goal of the interviews was to more appropriately guide the efforts of the project. EFL intended to use the data collected to gain more information about how changes to the environment and legal changes in the community are affecting the people who live there.

\section{MAHA OYA PROJECT}

In 2010, staff at EFL began to work with the riverbank communities along the western most portion of the Maha Oya. The Maha Oya is one of the longest rivers in Sri Lanka, at about one hundred and thirty kilometers ( 81 miles) long (Fernando n.d.). The name, Maha Oya, translated from Sinhala means Great River. This river basin is located in the wet zone of Sri Lanka and passes through four provinces before arriving at the Indian Ocean. For a map of the area see Figure 3. 


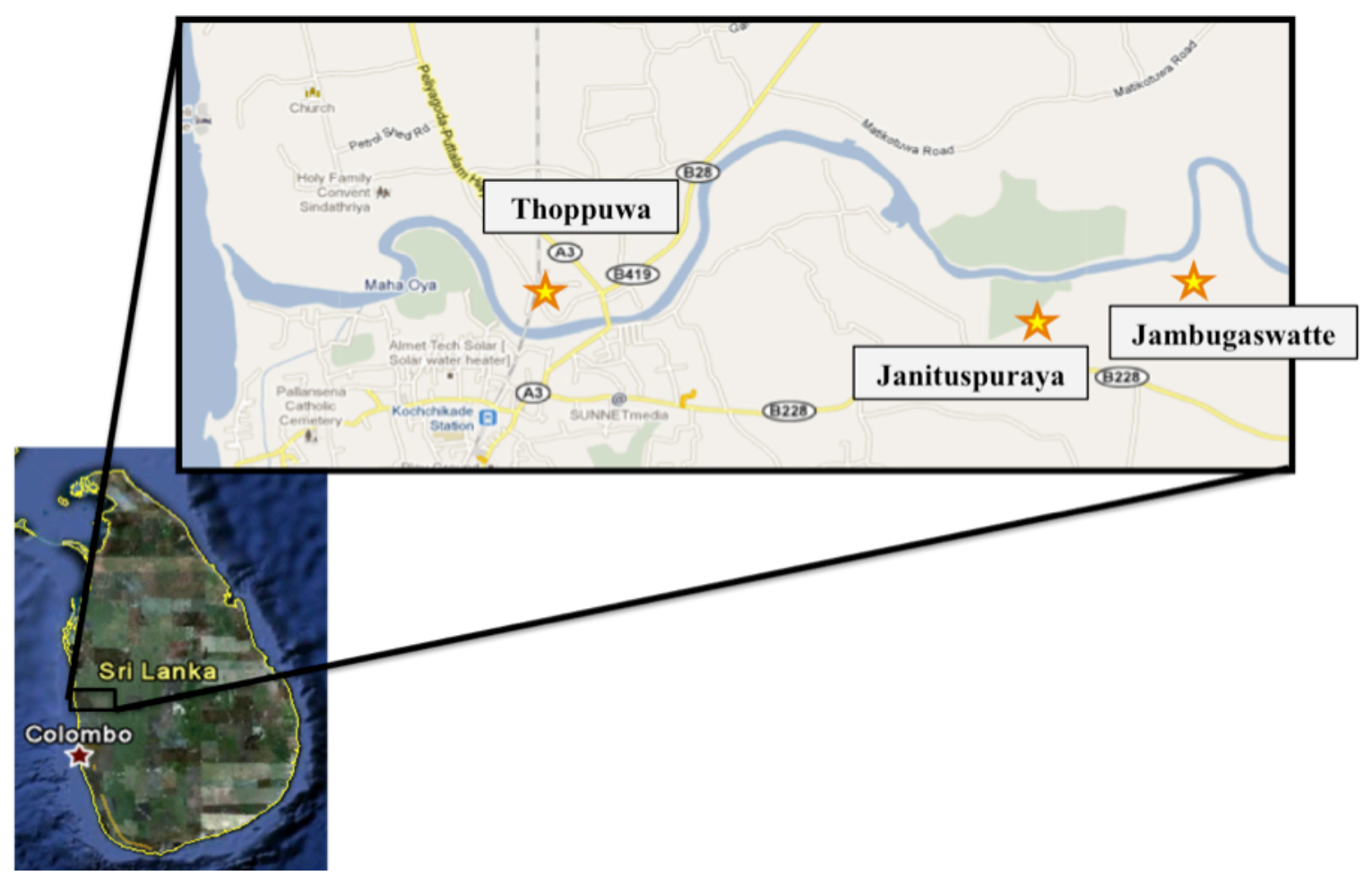

Figure 3: Map of Jambugaswatte, Janituspuraya and Thoppuwa

The primary goal of the Maha Oya project is to increase sustainability of the communities along an eight-kilometer (4.97 miles) portion of the Maha Oya (Environmental Foundation Ltd. 2009). One aspect of the project focuses on the introduction of alternative livelihoods. This is an especially important element because for many people in the area sand is the main source of income, an environmentally destructive occupation. In order to raise awareness about the issues of sand mining EFL has held a number of events - some with community leaders and stakeholders, others open to all village residents. Another part of the project is to hold programs for children at the local secondary school. EFL also monitors water quality and levels in the river and in nearby wells. The Maha Oya project is funded by a grant from 
Mangroves for the Future - part of International Union of the Conservation of Nature (IUCN) - and is one of six large grants in the region of South Asia ${ }^{1}$.

The emphasis on alternative livelihoods has led to the introduction of two main vocations to date. In July 2010 EFL sponsored a five-day training event-open to allwhich taught anyone interested the trade of shoe making. After this training event, some of the women who attended decided to join together in the formation of a women's association called Ran Liya ${ }^{2}$. Many of the women in the Ran Liya are married to sand miners, and the hope is that by making shoes they will be able to supplement their families' incomes, making it possible for their husbands to find work outside of sand mining. Figure 4 shows a few of the women of Ran Liya making shoes together at the home of one of the women.

\footnotetext{
${ }^{1}$ The official project title is: "Increasing the resilience of coastal and riverine communities to climate change and other threats, by conserving the ecosystem services of the Maha Oya and associated coastal wetlands in Sri Lanka."

${ }^{2}$ Ran Liya literally translated from Sinhala means gold women, however the meaning is understood as precious women.
} 


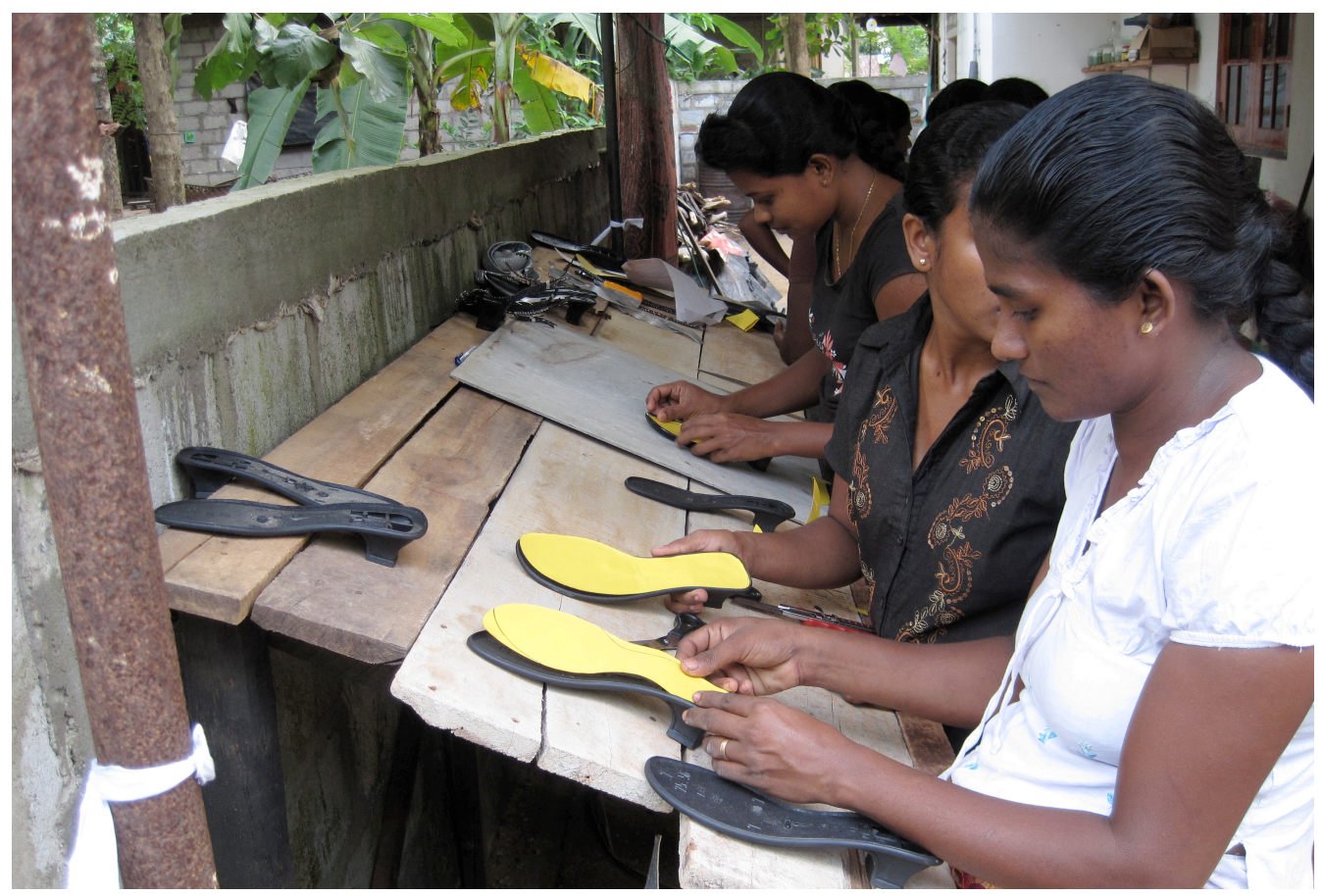

\section{Figure 4: Women of Ran Liya}

In another effort to introduce alternative livelihoods in the community, EFL sent three men to learn the trade of inland fishing. This training enabled them to pass on the knowledge to others in their home community. The men who attended the training joined with others in the community and helped guide the group in building a fishery for their own inland fishing operation in the village; this fishery while still under construction is shown in Figure 5. 


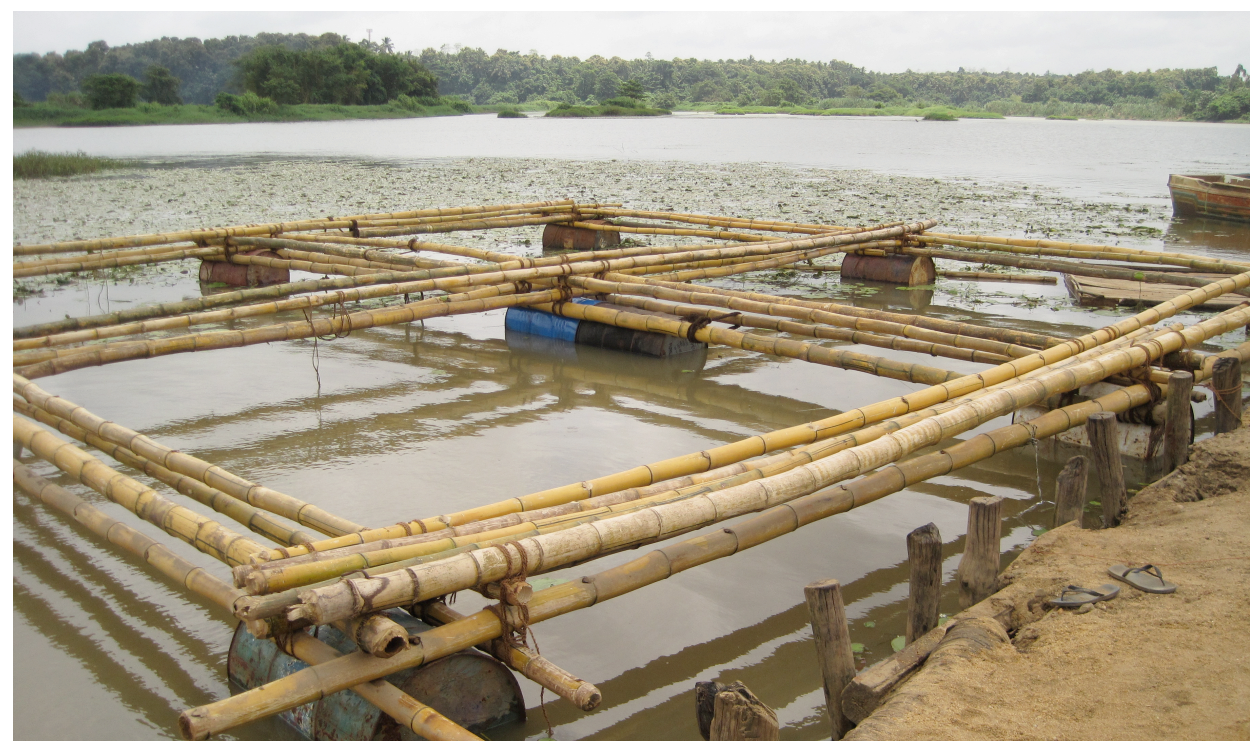

Figure 5: Site for Inland Fishing Operation

\section{ApPlied Sociology at EFL}

Since the staff of EFL is mostly comprised of environmental scientists and lawyers, they thought the skills of a sociologist would be useful. A sociological perspective is instrumental in generating a story of the lives of those most affected by sand mining. As EFL continues on with the Maha Oya project it is imperative that they know how people in the villages feel about sand mining as well as the changes happening in their communities. Creating a full picture of how people use and understand their natural resources helps to ensure that they are not left behind or pushed out of the discussion of new methods for resource management.

Social scientist Michael Cernea (2002) proposes that the success of development projects hinges on a social analysis maintained as an integral part of program design. In order to achieve this he advocates for social scientists to be included at every step of program design, not only in the traditional role as program evaluators. Cernea has 
contributed greatly to the body of knowledge for applied social science. In the 1990's he served as the Senior Social Advisor for Sociology and Social Policy at the World Bank. In this capacity he played an instrumental role in changing the way the World Bank views development and the value of a social science perspective. This view suggests that the people whose lives are affected by development must be involved in the changes in their communities. Similarly, Cernea notes that theories of development cannot be divorced from the social structures in which they operate (Bibbington 2006). Ideas for development may seem appropriate if applied theoretically to a community, but since each community comes with its own complexities, these need to be addressed case by case. It is for this reason that Cernea advocates for development policies to be understood directly in conjunction with how the particular community in question operates.

Interactions between people and environment are complex; the ideal goal is to support the sustainability of communities and the environment simultaneously. Due to the diverse elements present in a project such as this, applied sociology is a valuable tool in understanding the ways that people and the environment must work together.

\section{CONCLUSION}

The background provided in this chapter is meant to set the stage for those unfamiliar with sand mining and Sri Lankan village life, and provide reasons for why this project is important. In order to move forward in a study like this, it is vital to understand what is at stake for the communities involved. Sand mining is completely pervasive in the communities included in this study, while the necessity for healthy sustainable ecosystem is also vital. Village residents are simultaneously dependent on the environment and the destruction of it through sand mining. Likewise, my involvement with EFL was central to 
this project, and it is important to understand the role they play in these villages as they strive for the protection of the environment and the promotion of sustainable communities. All these elements are valuable to be aware of in order to fully appreciate the complexity of the situation on the Maha Oya. 


\section{Chapter 3: Literature Review \& Theoretical Framework}

The following chapter will review the literature relevant to this project as well as present the theoretical framework, which will be employed here. Generally the focus of this thesis is the conflict between the environmental and the social elements in this rural community; therefore an environmental sociological perspective is utilized to gain a greater understanding of the circumstances and challenges prevalent in the villages along the Maha Oya.

\section{EnVIronmental Sociology: An ApProach to Understanding the MAHA OYA}

The study of environmental sociology provides an important starting point for understanding issues with sand mining along the Maha Oya and the communities who are affected by it. Environmental sociology focuses on how social structures, culture included, are dependent upon ecosystems, and the ways in which humans contribute to, and are affected by, the destruction of environments. Additionally, environmental sociologists are dedicated to understanding how humans recognize and address current environmental problems (Heinrichs and Gross 2010). Michael M. Bell (2004) remarks that environmental sociology is the study of interactions and conflicts of the largest community, as it includes all life, the earth itself, water and air.

In the 1970's, William Catton and Riley Dunlap defined environmental sociology as "the study of interaction between the environment and society" (Dunlap 2002:331). Catton and Dunlap distinguish this from sociology of environmental issues by treating environmental conditions as variables in study. By this they intended to concentrate on understanding the relationship between social structures and the environment. For example they would investigate how social class and environmental pollution were 
interconnected, as opposed to simply asking people their opinions about the environment. Catton and Dunlap promoted the notion that despite the advances of modern industrialized societies, people are still dependent on the natural environment; thus environmental issues deserve attention within the field of sociology (Dunlap 2002). Maintaining environmental issues as important variables in social research offers a new way of understanding how human society is directly involved and affected by these concerns.

\section{FROM the Human EXEMPTIONALISM PARADIGM TO THE NEW ECOLOGICAL PARADIGM}

For a long time, the human exemptionalism paradigm (HEP) was the dominant sociological understanding of the human connection to the natural environment, emphasizing the fact that humans have the ability to control their surroundings. According to this paradigm, since human beings are able to create culture, language and technology, they stand separated and superior to the natural world. Also, cultural changes take place at a rate quicker than biological ones and can exist in limitless combinations, therefore, since humans have control over culture they have the special ability to alter any conditions that are thought to be objectionable. Likewise, culture has the ability to evolve and progress boundlessly; the complexity of human interaction is inexhaustible. In accordance with this paradigm it is in the endless cultural change that all problems will find their resolution (Vaillancourt 2010). This popular paradigm tends to lead people to believe that as humans we can always use our superior knowledge, technology and culture to relieve ourselves from the constraints of the natural environment. Maintaining an ideological stance such as this one stimulates little motivation to entertain sustainable 
management practices, as humans will always be able to adjust to, or alter, any changing or deteriorating ecological conditions.

Riley Dunlap and William Catton proposed a challenge to the prevailing HEP theory in the late 1970's. They promoted the adoption of an alternative ideology, which they called the new ecological paradigm (NEP). NEP claimed that despite the exceptional qualities humans possess, as with all other life, they are still subject to ecosystem constraints. Furthermore, characteristics like culture and technology are not capable of releasing humans from the limits of the natural environment (Dunlap and Marshall 2007). Likewise, the natural environment is made up of immensely complex and interconnected elements; thus with every action there are a number of unintended consequences that cannot be avoided, or even predicted, by humans (Vaillancourt 2010).

From the outset of sand mining in the Maha Oya, it is likely that sand appeared to be an abundant resource available for human use. However, as more and more sand was extracted in ever increasing amounts it became clear that it is an unsustainable practice at the current rate. Technology does not offer people in this community a way out of this predicament. Catton and Dunlap challenge the HEP because it is clear that humans are unable to predict or avoid the numerous unintended consequences of human action when it comes to the environment. The situation on the Maha Oya offers an important example of how societies can find themselves struggling to adjust the way they use and understand their ecosystems.

There are two main groups within environmental sociology. On one side there is the ecocentric view in which the drive is for environmental conservation is simply for the sake of the environment (Heinrichs and Gross 2010). In other words, the ecocentric view 
supports the notion that ecosystems have value on their own, separate from the needs of humans to take from the environment. On the Maha Oya this would play out if people were to see the river ecosystem as valuable and important even if it provided nothing for the well being of the humans in that area.

The other main view is the anthropocentric one, which focuses on the fact that the environment is necessary for human life, therefore providing motivation for the protection of natural ecosystems (Heinrichs and Gross 2010). In the anthropocentric view, protecting the environment is merely a by-product of maintaining human survival. The rational for conservation and preservation is the defining factor between these two perspectives. The two views diverge on what elements are most highly valued; in one it is the environment for its own sake; a mountain is valuable because it is part of the earth. Whereas in the other it is for human survival: a mountain is valuable because it provides timber and filters water supplies, two resources needed by humans. When considering this specific project, it stands to follow that these two views need to be merged, nature for nature's sake as well as for the benefit of humans. The true value lies in sustainability of social structures and the environment. The fact that humans need the environment to be healthy for survival, does not necessarily exclude them from appreciating nature for its intrinsic value. The two views do not have to stand in stark opposition to one another.

Similar to the conflicting ways of understanding the environment, either ecocentric or anthropocentric, traditional views of society and nature present a particular duality, in which people are simultaneously of nature as well as in opposition to it. Matthias Gross and Harald Heinrichs' (2010) description of this duality offers a greater understanding. 
For most classical authors, modern society remained in a dual relation with nature; society remains incorporated into nature and yet it stands opposed to it. In this view, nature is opposed to everything which is called human, to what is artificially worked and produced, to everything which is defining of society. (Heinrichs and Gross 2010:1)

As sociologists we must focus on understanding how the natural systems on which we depend can thrive along with human societies. Though this duality is a common way of thinking about nature and humans, it serves as an obstacle to multidimensional sustainability. Society must come to recognize its dependence and interconnection with the natural environment. And at the same time, we need not underestimate the importance of maintaining healthy social systems.

Recently there has been a shift in the field of environmental sociology, Heinrichs and Gross (2010) describe it this way: "the focus has been broadened from preserving the environment in its current status towards proactively shaping environment-societyconfigurations within the guiding vision of sustainable development" (Heinrichs and Gross 2010:5). This shift emphasizes the fact that scholars and development workers are looking toward manipulating natural environments and social structures in a way that can create sustainability on both fronts. Having a firm appreciation of how people understand and use their local ecosystems is vital to reshaping communities and environments to work more cooperatively together, for their mutual benefit.

FUNCTIONS OF THE ENVIRONMENT

Environmental sociologists (Dunlap and Marshall 2007; Harper 2008) commonly understand the environment in terms of the three main functions it carries out which are necessary for human society. These three functions are as supply depot, waste repository and living space. The natural environment provides humans with the materials needed for 
life, the supply depot. Included are things like food, provisions for shelter and fuel, and other resources. Waste repositories are important because all species, and to a greater degree humans, produce waste. The natural environment — through the earth, atmosphere and water - must be able to absorb or store this waste, all species depend on ecosystems to do this. Dunlap and Marshall (2007) point out that we have pollution when the earth can no longer absorb or store any more waste; as the earth's waste storage capacity is finite. Finally, people must have a place to live; the third function of the environment. Included in the study of living space is the ways it is altered because of human interactions with the environment, for example through deforestation or climate change (Dunlap and Marshall 2007).

This model is valuable because it emphasizes the importance of all three functions of the natural environment. Overuse of any one function is the root of environmental problems. Similarly, overuse of one function can inhibit the use of another function (Harper 2008). For instance, excessive pollution will put strain on the available sinks, which will limit the available living space in an ecosystem. In the past people were concerned that humans would exceed the limits of growth, meaning they worried about depleting food sources and living space. However, in contemporary times, exceeding the limits of growth addresses the imperative need for all three environmental functions to be accessible (Dunlap and Marshall 2007).

Understanding these three functions of the environment is extremely important for the purpose of this project. For the people who live along the Maha Oya, the resources provided by the environment are in conflict with one another; sand extraction limits access to clean water. Also, bank erosion from the overexploitation of sand challenges 
the availability of living space. This project speaks to the need for balance between these three important functions of ecosystems.

\section{Challenging The Tragedy of The Commons Ideology}

The situation along the Maha Oya presents a complex set of issues to be addressed. At first look it might be easy to assume that the natural environment is being destroyed because of open access to continued sand mining, an idea that falls in line with Hardin's Tragedy of the Commons model. However, upon further examination it becomes clear that the "tragedy" as Hardin describes it, is far too simple an explanation for what is really taking place. In order to understand the particular challenges to Hardin's model, we must first explore the ideas he put forth.

Resources that are shared by many people and have undefined property rights tend to pose management challenges. In the late 1960's Garrett Hardin (1968) presented a provocative look at how people utilize common resources; he referred to what he saw happening as the "tragedy of the commons." According to Hardin, the tragedy occurs because of a simple cost-benefit analysis on the part of individuals using a common resource. As a user of a particular resource - whether it is land for growing crops or sand from a river-an individual can calculate the direct benefit to them for having more of that resource. More land can mean more crops or cattle, increasing your income; more sand means greater income. All the benefits of taking more go directly to you. However, as resources are used, there is also an overall cost. These costs, though, are shared among all who use the resource, minimizing the direct cost to each individual. This pattern though, cannot continue indefinitely. As more and more people using a single resource make a similar assessment, the costs to all will become increasingly great; thus the 
"tragedy" is the devastation of the common resource.

In order to minimize the "tragedy" Hardin proposes protecting the commons through privatization. Despite the fact that for some resources-like air and water-it would be difficult to exclude people from using them, he still sees this as an appropriate method. Hardin advocates for the use of coercion, as he describes it: "mutual coercion, mutually agreed upon by the majority of people affected" (Hardin 1968:1247). By this he means that it would be most appropriate to force people into doing the right thing, and those most affected should decide the rules of use. He asserts that people will most likely not want to be coerced, but eventually they will understand that it is necessary and go along with it (Hardin 1968).

Upon superficial examination of the situation along the Maha Oya with sand mining, it would be easy to see how Hardin's concept has played out thus far. Sand miners can make the simple analysis that taking more sand from the river will provide direct benefit to them and their families in the form of a higher income. Sand is a valuable resource needed throughout the nation, so when the payout is great, the drive for exploitation is significant. In the short term, the costs of overexploitation are minimal to each person in the community - the water table may drop a little, waves may crash slightly closer to homes-factors that may go on unrecognized since the miners do not experience the true costs as individuals, they will continue to extract sand as long as they can.

However, this cursory explanation is one that ignores the complexities of what is really occurring. In a poor village with few other options for work, the economic opportunity of sand mining represents another plane of survival, not merely a job. 
Additionally, the destruction of the river tends to be obvious to people who live close to it, and given the opportunity for alternative forms of work, sand miners are likely to choose the less destructive path. In this community, two dimensions of survival are in conflict with one another; on one side there is the need for a healthy and thriving environment, while on the other side there is the need for the means to feed your family through economic gain. As is pointed out by Elinor Ostrom (2010), understanding overexploitation of natural resources in this context is detrimental to sustainable management. Essentially, it assumes that resources users are trapped in this cycle of overuse, affording them no agency to incite change or envision an alternative way.

From the time that Hardin wrote The Tragedy of the Commons it became a popular theory. When looking at natural resource use, in many instances it was easy to see how this idea was playing out in the real world. Increasing population leads to greater exploitation of natural resources, further supporting the tragedy of the commons ideology. Although, as mentioned previously, the way Hardin thought that people would fall easily into overusing natural resources is an overly simplistic view of what is really happening. Interestingly, Hardin even suggested that for rural communities, as environmental exploitation-or the tragedy-becomes obvious it would be likely that they would be unable to properly manage natural resources, even if they had been able to do so in the past.

This way of understanding how people use resources calls for the implementation of a heavy-handed approach to deal with environmental problems (Agrawal and Gibson 1999). However, upon implementation of such top-down oversight the outcome is often that government-imposed regulations tend to alienate the communities they are intended 
to support. Ostrom (2010) suggests that although Hardin may have accurately understood the challenges associated with common resources, his end analysis was inappropriate as it "predicted the impossibility of self-organization and prescribed only two solutions-both of which had to be imposed on resource users" (Ostrom 2010:322)

Having a firm grasp of Hardin's theory on the commons and its rise in popularity is an important step in understanding how it is challenged. In the years since The Tragedy of the Commons was written there have been a number of scholars who have questioned the concept. In The Drama of the Commons (Dietz et al. 2002) the authors discuss some of the downfalls of Hardin's proposal for government/coercive management of natural resources. For one, it tends to alienate indigenous people from their land traditional methods of managing resources. Often, power is taken away from those using and living within a particular resource area and put in the hands of those with little connection or understanding of it. However, when power changes hands and is given to government entities we see that in most cases governments lack the appropriate resources to properly implement management. In the face of insufficient management, resources are put at risk of being exploited and degraded even quicker.

Coercive top-down methods have proven to be an ineffective approach for management; this is especially true in the case of resources necessary for survival (Ballet, Sirven, and Requiers-Desjardins 2007; Agrawal and Gibson 1999; Ostrom 2010). Dietz et al. (2002) explain that the common outcome of this type of management is for the resource to be degraded at a faster rate and resource users put at a greater disadvantage. As mentioned before, often states do not have the resources necessary or properly trained personnel to take on management. So with the power in the hands of the state, an entity 
unable to control usage, resources essentially become open access, leading to quicker degradation. Also, with a culture of corruption, widespread in many government institutions, officials may be paid off to allow access, a problem common in a number of places, Sri Lanka included (Sri Lanka Water Partnership n.d.).

In Sri Lanka, due to the obvious problems associated with unregulated sand mining, the government tried to maintain control by dictating what methods are used and the quantity of sand mined. The goal was to implement oversight through the Mines and Minerals Act of 1992, and the creation of the Geological Survey \& Mines Bureau (GSMB). Prior to the creation of this system, sand mining was managed by local administrations; this means the people in charge of oversight were physically present in the regions under their charge, allowing them to fully understand all the issues relevant in each area. This system was nevertheless a flawed one, as the river was still threatened, however at least those in charge of management were in contact with the resource users. Beginning with a structure where managers, users and communities are collectively involved creates the potential for sustainability. After the creation of the GSMB, however, power was pulled away from local administrations and placed in the hands of a single centralized institution. With no one present to be directly responsible for management the result has been that it is easy to take advantage of the system and continue illegal mining.

As the Sri Lanka Water Partnership points out, "restrictions on one hand and increased demand on the other has seen a steep price increase in sand, resulting in illicit mining operations spreading to almost 35 rivers and tributaries" (Sri Lanka Water Partnership n.d.:1). Since the Sri Lankan government is operating under inadequate 
resources to deal with sand mining, the entire system is rife with corruption. Essentially, the effect has been that no one is regulating the extraction of sand from Sri Lanka's rivers; government intervention in this issue has proven to be wholly ineffective. In this example, it is clear to see how the concerns raised by Dietz et al. are entirely warranted.

Though Hardin's ideas about natural resource use were popular, it is important to see how it is an inadequate understanding of what is truly happening in most cases. Despite the fact that sand miners may only be faced with slight costs for the continuation of sand mining, they are still in a position to see how it is destroying the environment of their communities. Hardin does not allow for this type of conflict when describing the tragedy of the commons. Additionally, the recommendation for top-down government management has been proven ineffective. As Ostrom (2010) points out:

Once analysts perceive human beings as being trapped inside perverse situations, however, the subject to whom reform is addressed is external to those involved. Instead of viewing analysis as providing better insight to enable those who are affected by perverse situations to alter the incentive system they are facing, the purpose of scholarly modeling and analysis is seen as providing advice to an external government or a "social planner" as to how to impose a new structure on those individuals. (321)

Taking resource users out of the management system only serves to alienate them and allow for greater destruction.

Conservation of natural ecosystems is vital for the sustainability of nature and communities. However, as Arun Agrawal and Clark Gibson point out, these two interests, nature and community, are often seen in opposition to one another. Understanding the problem in this context, though, tends to ignore the fact that communities have a direct stake in wanting their ecosystems to operate in a sustainable way. Survival in one realm is intimately connected to survival in the other realm. 
A convincing logic undergirded the belief that the goals of conservation and the interests of local communities were in opposition: Conservation required protection of threatened resources: wildlife, forests, pastures, fisheries, irrigation flows, and drinking water. Members of local communities, however, rely on these resources for their fodder, fuelwood, water and food and thus exploit them without restraint. (Agrawal and Gibson 1999:631)

Along the Maha Oya, the exploitation of sand from the river provides a livelihood, either

directly or indirectly, for the majority of people who live there. Furthermore, the health of the ecosystem is vital to the community's well being. Village residents are invested simultaneously in the continuation of sand mining and ecological sustainability. As is suggested by Agrawal and Gibson, it would be quite ignorant and inappropriate to simply tell people to stop mining sand because it is destructive to the environment. But, because of this conflict in values, it tends to appear as though communities are anti-conservation; however, in this context, conservation should address the need for balance between these two seemingly conflicted principles. The key here is to envision a system where these two interests can work together instead of in conflict with one another, because in the end, the goals are the same.

\section{COMMUNITY}

In the late nineteen-nineties, natural resource management scholars shifted focus away from the top-down coercive methods to a more inclusive community participation model. Since this is an important aspect of this study it is vital to first explore what makes a community. The traditional way of understanding communities is to see them as cohesive units in which members are relatively homogeneous. Offering a challenge to this narrow view of communities, Agrawal and Gibson (1999) acknowledge that diversity exists even within small communities, a valuable point to fully acknowledge. 
But because it views community as a unified, organic whole, this vision fails to attend to differences within communities, and ignores how these differences affect resource management outcomes, local politics, and strategic interactions within communities, as well as the possibility of layered alliances that can span multiple levels of politics. (Agrawal and Gibson 1999:633)

People will tend to understand the natural resources around them within the context of how they utilize those resources. In fact, it would be a mistake to claim that an entire village would have a single perspective on how resources should be used or managed. It is for this reason that exploring these ideas through the use of in-depth interviews with community members is so important. It is vital to appreciate the diverse perspectives among resource users, village residents and the various stakeholders.

Communities are often seen as having three main elements: they cover a relatively small space, they have a homogenous social structure, and they have shared norms. Agrawal and Gibson (1999), however, suggest that this narrow understanding of what makes a community and how it operates is detrimental to the success of natural resource management and sustainability. Instead of concentrating on the three elements of community as stated above, Agrawal and Gibson (1999) offer alternative characteristics of communities, which are more significant to common resource management. For one, it is important to understand the diversity of perspectives and interests among community residents. Different stakeholders will have different opinions of how resources should be used. In the case of sand mining, there are national interests in the continuation of sand mining, which also feed into this conflict. Sand is a necessary resource for building, so even those who are not directly involved in mining have a stake in the further exploitation of sand. 
Another element of communities that deserves attention is understanding the current local social structures. Communities have a number of local level negotiations that address issues within the community, including the way natural resources are used. Institutions like the state or NGOs influence the workings of communities. These outside forces are important to understand as well as the local ones. Similarly, Agrawal and Gibson (1999) note that organizations are not the only source of outside influence on communities. For example, in Sri Lanka the tsunami 2004 created a greater need for sand because of rebuilding efforts, the rising demand leading to a higher market value.

\section{CONCLUSION}

This review of relevant literature and the exploration of environmental sociology as a theoretical framework will be used as a guide when analyzing the data collected during this study. Environmental sociology provides an appropriate foundation for understanding the ways in which communities and environments must cooperate for the mutual benefit. This project highlights the complexities of having two aspects of survival -economic and environmental-in conflict with one another. 


\section{Chapter 4: Methodology}

This chapter provides a detailed description of the methods used for this study. This project utilizes in-depth, semi-structured interviews. The outline of research design includes a rationale for using qualitative methods and gives special attention to concerns of translation and cultural appropriateness. Elements of data collection are presented including setting, recruitment, instrument and interviews; this project utilizes in-depth, semi-structured interviews. Further, methodologically relevant limitations of this project are discussed. Finally, this chapter presents a description of the data analysis process employed for this study. The Portland State University Human Subjects Research Review Committee granted approval for the completion of this study prior to the start of data collection.

\section{RESEARCH DESIGN}

\section{RESEARCH QUESTIONS}

1. How do village residents along the Maha Oya perceive sand mining?

2. What are the emotional, practical and theoretical responses of village residents to the effects of sand mining on their local ecosystems?

Question one addresses the need to truly explore how residents of these villages understand sand mining. Since they are the people most closely affected by the economic opportunities associated with sand mining and the environmental degradation it is necessary to construct a full picture of how they view and address the situation. In order to promote community-based management for this resource, this research question provides a needed background understanding.

Question two addresses the fact that it is also important to assess how residents understand the connections between sand mining and their natural ecosystems. If people 
are experiencing increased environmental problems in their community due to sand mining, but are not making the link between the two, this is important to know. When people truly understand the consequences of a particular action they are then in a better position to fully affect change for sustainability. In an effort to understand what variables will contribute to communities being able to self manage natural resource use; Elinor Ostrom (2009) came up with ten main factors to consider. One variable is knowledge of the social-ecological system. By this, Ostrom suggests that it is vital for resource users to have a distinct understanding of how it functions ecologically and also how various stake holders are interconnected around it.

\section{QUALITATIVE APPROACH}

For the purpose of this study, I conducted fifteen in-depth qualitative interviews. Participants' responses serve as the data for this project. Qualitative methods, as employed here, allow participants to give details about their lives, experiences and expand upon personal opinions. While quantitative methods are useful in gathering a great deal of data and identifying trends, they are not effective for understanding the perspectives and experiences of individuals. The issues with sand mining along the Maha Oya are complex and span across many aspects of life. The exploitation of sand continues to flourish providing an income to many people, while at the same time causing environmental destruction. The methods used thus far to limit the amount of sand taken from the river have proven to be ineffective, so there must be a new way forward that takes all the issues into account. In order to focus management strategies more effectively and gain community support while addressing the multi-dimensional ways that people interact with the environment it is important to understand how people perceive this 
issue. In order to fully appreciate the concerns associated with sand mining qualitative tools are the most appropriate for this type study.

$D E S I G N$

In order to capture each participant's personal experiences and opinions as data, I used an in-depth semi-structured interviewing approach. Using a guide of open-ended questions the goal was to facilitate a conversation with the participants. During this type of personal exchange there is opportunity to probe for particularly useful information or ask for immediate clarification when needed. Interviews are an advantageous method because they provide great depth and quantity of data for each participant.

The use of grounded theory, as described by Kathy Charmaz (2006) is central to this project. "Grounded theory methods consist of systematic, yet flexible guidelines for collecting and analyzing qualitative data to construct theories 'grounded' in the data themselves" (Charmaz 2006:2). These methods dictate that the researcher remain careful as to not simply fit the original intentions of the research into the data; instead it is vital to allow theories to emerge from the data. An important element of grounded theory is the regular return to the literature, which helps the researcher stay true to the participants' experiences by continually contemplating alternative theories and explanations for presented phenomena. The flexibility of grounded theory allows for research elements to evolve as needed through an iterative process. For example, after the completion of three interviews the guide was edited so that the questions were worded and ordered in a more appropriate way. The main goal of grounded theory is to create an analytic understanding of the lives of the participants. For the purpose of my project this is a valuable approach 
because it puts all the focus on ensuring that voices of the individual respondents are central to theoretical understanding of the multifaceted concerns of this research.

In keeping with the guidelines of a grounded theory approach to research, this project was highly influenced by the experience of being an intern for the Environmental Foundation Ltd. Though the main source of data for this study comes from in-depth interviews, the study as a whole was influenced by participant observation. Prior to conducting any interviews I visited the communities along the Maha Oya with EFL staff. This experience allowed me to be a part of the various project components and also gain a first hand understanding of the issues surrounding sand mining. These visits to the field were valuable for informing the direction and wording of the interview guide. Likewise, I was able to watch sand miners at work, which allowed me to appreciate the importance and complexity of this industry.

\section{TRANSLATION AND CULTURAL APPROPRIATENESS}

Since the majority of the people in the villages included in this study do not speak English, and I do not speak Sinhala, a translator was necessary. Priyanka Mudalige, ELF staff member, worked as a Sinhala and English translator. Josephine Pui-Hing Wong and Maurice Kwong-Lai Poon (2010) argue that it is vital to include translators in the research design process and maintain them as important partners in conducting research. It is for this reason that prior to beginning any interviews, Priyanka and I spoke a number of times and I thoroughly explained the study's purpose. At this point, Priyanka took on another role and served as a key informant, though she is not from the village, she is familiar with Sri Lankan village life and has worked in this community for an extended time. As an outsider to the community, I needed guidance to ensure that all questions 
were culturally appropriate. Likewise, the wording of each question was important to make certain that what was actually being asked was in line with what was intended. Priyanka reviewed all drafts of the interview guide, and helped to ensure that the questions were appropriate and that they elicited the types of information necessary for the study.

\section{Data Collection}

SETTING

Throughout the course of this project, I interviewed men and women who live in three different villages along the Maha Oya in the Western and North Western Provinces of Sri Lanka. Three villages were identified for their proximity to the river and EFL's familiarity within the community: Jambugaswatte, Janituspuraya and Thoppuwa. Refer back to Chapter 2 (Background) for more information on the villages and their geographic location, as well as Map 1, which shows the location of the three villages in Sri Lanka.

RECRUITMENT AND PARTICIPANTS

The goal of this study is to speak with people whose lives are directly connected to the river. The villages selected are based on the EFL project area. All participants are residents of one of these three villages, Jambugaswatte, Thoppuwa or Janituspuraya, which are in close proximity to the Maha Oya. Because of the setting of this study, recruitment was done in person. My translator and I walked around the village and visited homes at random, once there we explained the basics of the study. Since, in most cases there was only one person there at the time of explaining the study, we asked if they would like to participate. Demographic data for the participants is presented in Table 1. 
We obtained verbal consent from each participant to be part of this study; a method approved by the Portland State University Human Subjects Research Review Committee.

Table 1: Participant Demographics

\begin{tabular}{|c|c|c|}
\hline \multirow{2}{*}{ Gender } & Male & 7 \\
\cline { 2 - 3 } & Female & 10 \\
\hline \multirow{4}{*}{ Age } & $<25$ & 2 \\
\cline { 2 - 3 } & $26-35$ & 3 \\
\cline { 2 - 3 } & $36-45$ & 5 \\
\cline { 2 - 3 } & $46-55$ & 4 \\
\cline { 2 - 3 } & $56-65$ & 1 \\
\cline { 2 - 3 } & $>66$ & 2 \\
\hline \multirow{3}{*}{ Village } & Janituspuraya & 1 \\
\cline { 2 - 3 } & Jambugaswatte & 10 \\
\cline { 2 - 3 } & Thoppuwa & 6 \\
\hline
\end{tabular}

Though I did not ask directly, it is implied due to the general demographics of the area sampled and the use of Sinhala in interviews that the majority (if not all) of participants are Sinhalese. Questions about ethnicity were not included for two reasons. For one, Sri Lanka had been engaged in a civil war since 1983, which only ended in 2009. Foundational to this conflict is the inequality between the Sinhalese majority and the Tamil minority led by the Liberation Tigers of Tamil Ealam (LTTE) (Rob Johnson 2005). Also, there is no indication that ethnicity plays a significant role in sand mining or property rights over natural resources in this region. Data from the 2001 Sri Lankan census further indicates that Sinhalese is the largest ethnic group in the region, which falls within two districts in western Sri Lanka: Gampaha 90.98\% Sinhalese and Puttalam 73.71\% Sinhalese (Department of Census and Statistics 2001). Table 2 provides a break down of other ethnicities in the region, which include Sri Lankan Tamil, Indian Tamil, Sri Lankan Moor, Burgher and Malay. The 2001 data are the most recent available. 
Table 2: Ethnicity by District

\begin{tabular}{|c|c|c|c|}
\hline & Gampaha & Puttalam & Total \\
\hline Total & $2,063,684$ & 709,677 & $2,773,361$ \\
\hline Sinhalese & $\begin{array}{c}1,877,545 \\
\mathbf{9 0 . 9 8 \%}\end{array}$ & $\begin{array}{l}523,116 \\
\mathbf{7 3 . 7 1 \%}\end{array}$ & $\begin{array}{c}2,400,661 \\
\mathbf{8 6 . 5 6 \%}\end{array}$ \\
\hline $\begin{array}{c}\text { Sri Lankan } \\
\text { Tamil }\end{array}$ & $\begin{array}{l}65,302 \\
\mathbf{3 . 1 6 \%}\end{array}$ & $\begin{array}{l}48,072 \\
6.77 \%\end{array}$ & $\begin{array}{r}113,374 \\
\mathbf{4 . 0 9 \%}\end{array}$ \\
\hline $\begin{array}{l}\text { Indian } \\
\text { Tamil }\end{array}$ & $\begin{array}{l}7,621 \\
.37 \%\end{array}$ & $\begin{array}{l}2,227 \\
\mathbf{3 1 \%}\end{array}$ & $\begin{array}{l}9,848 \\
.36 \%\end{array}$ \\
\hline $\begin{array}{c}\text { Sri Lanka } \\
\text { Moor }\end{array}$ & $\begin{array}{l}78,705 \\
\mathbf{3 . 8 1} \%\end{array}$ & $\begin{array}{l}133,134 \\
\mathbf{1 8 . 7 6 \%}\end{array}$ & $\begin{array}{r}211,839 \\
\mathbf{7 . 6 4 \%} \\
\end{array}$ \\
\hline Burgher & $\begin{array}{c}11,093 \\
.54 \%\end{array}$ & $\begin{array}{l}735 \\
.1 \%\end{array}$ & $\begin{array}{c}11,828 \\
\mathbf{. 4 3 \%}\end{array}$ \\
\hline Malay & $\begin{array}{c}13,683 \\
.66 \%\end{array}$ & $\begin{array}{l}1,214 \\
.17 \%\end{array}$ & $\begin{array}{l}14,897 \\
.54 \%\end{array}$ \\
\hline Other & $\begin{array}{l}9,735 \\
\mathbf{. 4 7 \%}\end{array}$ & $\begin{array}{l}1,179 \\
. \mathbf{1 7 \%}\end{array}$ & $\begin{array}{l}10,914 \\
.39 \%\end{array}$ \\
\hline
\end{tabular}

(Department of Census and Statistics 2001)

SAMPLE SIZE

The foundation of this study is data collected from fifteen interviews with seventeen participants. For the purpose of qualitative studies, such as this one, it is important to collect data until saturation is reached; at which point, responses are repeated and no new themes that arise. With the aim of creating guidelines for knowing how many interviews are enough, Greg Guest, Arwen Bunce and Laura Johnson (2006) use their study of sixty female sex workers in West Africa as a test of saturation. They determined that no significant new codes arose in the data after the first twelve interviews. Guest et al. (2006) justifies these findings by outlining the important features of their study, which facilitate the use of a small sample size. The interviews must be structured so that each participant is asked the same set of questions. The content of the interviews must be in a domain that is widely known to those being interviewed. Finally, 
participants should represent a relatively homogenous group, and there should be an expressed goal of understanding participants' opinions and perceptions. In flowing these guidelines, Guest et al. (2006) suggest that it is possible to reach saturations with a fewer number of participants. For a study of this nature, it is appropriate to use a sample size of fifteen interviews.

In addition, Guest et al. (2006) note the importance of these findings for applied research projects, because it is essential for researchers to be able to state how many interviews will be needed, prior to beginning research. This is an important point for this project. EFL provided a staff member to translate for me, taking resources from the other work of the organization. Therefore, it was necessary for EFL to allocate the appropriate number of work hours to the project. Having a goal in mind at the start of research enabled them to accurately assess the project demands.

\section{INSTRUMENT}

Previous research and preliminary informal conversations with community members informed the interview guide. Input from Priyanka, my key informant, was also fundamental to the creation of the guide. The interview guide used is presented in the Appendix. Questions in the guide were divided into these four categories: demographics, water, sand mining, and environment and community. Questions about water aimed to get a view of any water related problems and where people get their water. In the sand mining section the goal was to explore what people know about sand mining and its effects on the environment, as well as their connections to sand mining and overall opinions about it. In the last section the questions aimed at understanding peoples relationships with their neighbors and also general stance on the environment. I believe 
that questions about household income would have been culturally inappropriate therefore they were left out.

\section{INTERVIEWS}

I conducted fifteen interviews, with a total of seventeen participants. The discrepancy in numbers is because two interviews were conducted while both husband and wife were present. Within the village setting it would have been inappropriate to ask the spouse to leave or not participate so I spoke with them together. Similarly, during a number of interviews other family members were present. Usually, others present would only listen to the conversation, though in a few instances they contributed their own comments. This could be beneficial, as it would gather a greater breadth of information. However, having other people around also could have inhibited participants from saying something that they did not want others to know.

Each participant chose where to have the interview take place. The majority of interviews were conducted on participants' porches or in their living rooms. Each of the interviews lasted between thirty and sixty minutes.

Because I am an outsider to the communities I was interviewing it was especially important to create an interactive framework in which participants felt comfortable in talking with us. In order to do this I asked Priyanka to explain that anything they said would not be shown to anyone else, and I would not include their name or any identifying information in the report. I also emphasized the fact that there are no right or wrong answers and since they are the experts it was my goal to learn from them. Through my internship with EFL I was able to spend time in the villages prior to doing any interviews. This experience allowed me to be a known face to at least some people in the community, 
which I believe to have made respondents more willing to speak with me. Also, some people we talked with were familiar with Priyanka, offering me credibility.

During the interviews Priyanka was also able to give me immediate clarification on certain things that I may not have otherwise understood. Since she had a firm understanding of the study though preliminary conversations with me, she was able to help probe for particularly important information. Also, the time between interviews was an opportunity for us to discuss some things that came up and for me to gather a greater understanding; this was especially true for details particular to village life in Sri Lanka. For example, one woman talked about why she and her daughters did not go out much or socialize with others in the community. Essentially, she said that since her husband was often away and she has four daughters at home they do not socialize very much. This is because it might be seen as inappropriate to have people coming and going from the house while her husband is gone. Though I understood what she told me, after the interview Priyanka was able to explain further that what she was describing is a common value for many families in Sri Lankan villages.

All interviews were digitally recorded; I then transcribed all the English portions. All notes taken during the interviews were also transcribed to aid in the analysis process. After the completion of the interviews, I hired a professional translator to listen to the recordings and translate them a second time and create an English transcript of all spoken Sinhala.

Keeping memos is a valuable research tool when doing qualitative research. Memos are notes to the researcher, which facilitate remembering the process and events of the research. Throughout data collection, analysis and writing I wrote careful memos 
to myself to keep track of things that arose. Likewise, while in the field I took notes to aid in remembering details about the setting and events in the field.

\section{LIMITATIONS}

My connection to EFL facilitated the completion of data collection, although it is important to explore the ways that this connection could have also inhibited interactions with community members. If people knew I was connected to them, they may have been hesitant to be honest about their feelings concerning sand mining, knowing that EFL is an environmental organization. Similarly, if a person had negative feelings about the work that EFL was doing, they may have been reluctant to talk to me at all. Nevertheless, I believe this influence to have been minimal. Though people had seen us around the village many people we interviewed were generally unaware of what EFL was and what they were doing in the village.

During the recruitment process we approached about eight people who declined to participate. There are a few possible explanations for why people may have chosen not to be part of the study. Some, seeing a foreigner, may have thought they would have to respond in English, and refused before we were able to explain otherwise. Some people told us they could not take the time to talk to us. Others became hesitant when they heard there would be questions about sand mining. In at least one instance, a known sand miner refused to be interviewed. Since sand mining is a central issue to this project special attention was placed on including miners, though they were also the most reluctant to be interviewed. This is most likely because many miners are engaged in illegal mining activities. More implications of the refusal rate will be examined in the discussion chapter. 
Despite the fact that I had a translator working with me, the language barrier between the participants and myself is a significant limitation. The flow of conversation is disrupted and less natural when everything must be translated, making communication more difficult. Priyanka's translating was vital to the success of this project; however, it is important to note that though she is bi-lingual-in Sinhala and English-she is not a professional translator. A consequence of not having a professional translator is that some parts of the conversation may not have been conveyed as accurately as is necessary. Hiring a professional translator to translate the recordings was intended to minimize this limitation.

\section{Data AnAlysis}

First of all, it is important to acknowledge the fact that since the interviews were conducted with a translator in English and Sinhala the responses of each participant shows up in the transcript twice; once in the translated words of the participant and a second time interpreted by my translator during the interview. Throughout the data analysis process, I used the direct translation from the interview audio recording, of the participants' responses, as I believe this to be the most accurate representation of their responses. However, having both the direct translation and the interpretation provided by my translator at the time of the interview in conjunction with one another was often valuable for understanding the full meaning of what was being said.

\section{SUMMARY}

The use of in-depth interviews is the most appropriate method for understanding the perspectives and experiences of each person involved. Similarly, the setting of this project meant that the research design needed to be flexible enough to change as 
circumstances changed or new elements came up, it is for this reason that the use of a grounded theory approach was so important. Conducting a research project outside of your home country does present a number of obstacles that need to be taken into consideration. Throughout the course of this study it was important to remain vigilant in ensuring that as a researcher and an outsider I was always considering how to be culturally appropriate. 


\section{CHAPTER 5: FINDINGS}

During the course of the fifteen interviews conducted for this study there were a number of main themes emerged. The major ideas that emerged in the interviews have been grouped into related headings. The main topics are as follows: general opinions about sand mining, connecting sand mining and the environment, communication about sand mining, economic dependence on sand mining, legal concerns with sand mining, social problems associated with sand mining, water related issues, support for the continuation of sand mining, and gender and the environment. Quotes in support of these themes are also presented in this chapter along with a description of each one.

\section{General Opinions about SANd Mining}

In the community where this study took place, sand mining is a huge part of everyday life, even for those who are not directly involved in it. Because of this, most all people have something to say about sand mining in one way or another. The following section aims at offering an overview of general opinions about sand mining.

Participants of this study were often very aware of the consequences to others in the community if sand mining were stopped, especially when it comes to people being able to access this source of income. Respondents tended to be simultaneously aware of the adverse environmental consequences of sand mining as well as the need for its continuation for economic reasons. In the way people talk about sand mining it comes through that there is a struggle between these two values. On the one hand, they value the environment they live in and need for survival. A number of participants spoke about the specific changes they have seen in the river over time. Two of the main issues people point to are river bank erosion and the deepening of the river causing it to be more 
dangerous. On the other hand, though, respondents appreciate the fact that their neighbors (and themselves in some cases) need to make a living to support their families; sand mining is a necessary mode of economic survival. Even in a single statement, respondents tend to struggle between the environmental and the economic.

Annika: "Yes, mining is a sin. There was only the river there and there were about a hundred houses, now those are all cut off. Now people can't even go that side to see the river, it's not beautiful anymore. It's like a range." - "There is a lot of harm caused by sand mining. But for a lot of people in this area it is the only source that brings food to their plate. Otherwise it is harmful in every other way. Trees are being cut down. In that area I don't think the water is in a condition for people to drink even in an emergency. A lot of harm is being done."

Annika is a nineteen-year-old woman, the youngest person included in this study. She articulates the fact that sand mining for many people translates to food for their families. Though at the same time, she acknowledges her own opposition to the practice for the way it is affecting her home and the environment she, and others, need.

Rajeev: "I think it's not good. I'm not saying its bad more than 10\%; about $90 \%$ is good. But our children's children will face trouble regarding the environment. Generally, people do not like it."

Rajeev talks here about how not all aspects of sand mining are bad. However he then also acknowledges that future generations will have serious problems to deal with because of sand mining. It is particularly interesting that Rajeev says that sand mining is ninety percent good, but then he also says that most people do not like it. When talking to residents about sand mining there is a very clear conflict in their opinions about it.

Nabeel: "There are two problems here. One is...there are two sides to it. One side is stronger; other side is people's addiction. People are addicted to this because there is more money in it. So no one wants to focus on any other job...this is not like that, they can earn two or three thousand rupees from it." 
This man, Nabeel, is addressing the fact that many sand miners are unwilling to explore other economic options because they are able to earn a decent income from what they are doing now, it makes them reluctant to look into other ways of making a living. He even uses the word addiction to describe why people continue to mine sand, referencing the experience to being like a drug.

Manuri: "Yes, in this area they do sand mining. Now it's been banned but I think they still continue to do it secretly (laughing)." - "I think they are mining sand around the corner, no matter how many times they've been stopped they still do it. So it's inconvenient for people who go to bathe. Sometimes because of sand mining that area becomes deeper...therefore...little children go there to bathe...problems like that."

This woman understands that sand mining has been banned, though she also knows that it is still done. The fact that people continue to mine sand illegally is no secret or surprise to those who live in these communities, and even throughout the country. In many ways the corruption and bribery that happens in relation to sand mining is thought to be just the way things are done. Manuri is also well aware of the problems created by sand mining.

\section{CONNECting SANd Mining AND THe EnVIRONMENT}

Sand mining has proven to be an environmentally destructive industry, the review of literature on sand mining has pointed to a host of complex problems as a result of this practice. Participants who were interviewed during this project referred to a range of problems they have seen happening in their village along the Maha Oya. One of the most immediate problems for many people is the falling water table; wells are running dry, causing problems daily for the residents of these villages. The following quotes exemplify how residents are making the connection between sand mining on the Maha Oya and the dropping water level in their own family wells. 


\section{FALLING WATER TABLE}

Manuk: "Because we dig out the sand the river banks get washed away. The river gets deeper and deeper so the water in upper level flows down to the river because of this one day water level in this area will go down." - "That means our water level will go down more than the sea level. Therefore to fill up that excess water level we need to give the water that is here to balance the water level in the river."

This response came from a young man who is involved in sand mining. He displays a strong understanding of the connections between sand mining and the falling water table; he offers an explanation of the ecological processes at work. Also, Manuk includes himself in this statement; he fully acknowledges that he is partially responsible for this current ecological problems surrounding sand mining.

Dulani: "We had to dig 50 feet due to sand mining. Water level also goes down because of sand mining. In future our children have to dig deeper to get water."

Another woman tells of how her family had family had to dig their well down to fifty feet just to get enough water. Prior to this statement she mentioned that their well was only twenty feet deep, which means they had to dig another thirty feet in order to get water. She understands that this has been happening as a result of excessive sand mining on the Maha Oya.

Dineeka: "Because of sand mining, sometimes drinking water for the people is getting less. When they are digging on that side, water in this side dries up. Like that, harmful things do happen to the environment."

Annika: “Yes. Now in our well the water has gone down, we didn't have much rain also. I think due to sand mining something must be happening to the water, maybe something is happening underground. So now there isn't much water in the well. Within a few days the well will dry out. There are several issues like that regarding water."

Dineeka has made the direct connection between the dwindling water supply and sand mining on the Maha Oya. During another part of the interview with her, she mentions 
that she does not know much about sand mining, though she still understands that there is a connection between this industry and the water supply. Similarly, Annika, a young woman also speaks about the fact that there is not enough water in their family well. She talks about how she suspects that sand mining has caused this problem, though she is not sure exactly what is really happening.

\section{LOSS OF LAND AND EROSION}

For the people who participated in this project, loss of land came up a number of times as another detrimental effect of sand mining. Several respondents noted that because of riverbank erosion and large excavated pit mines the community has seen a dramatic decrease in the amount of productive land available. Sand mined from the river causes the banks to become unstable allowing more and more land to fall into the river, along with any vegetation growing there.

Aashik: "That day we went to the other side with the doctors, on that side the river is on the land. I also have one acre of land there, I have the deed but the land is not there, it's under water."

Aashik is a fifty-four year-old man who has lived in the village of Jambugaswatte for his whole life, meaning that he has been around to see many years worth of changes in the community. He talks about the fact that land is being lost due to excessive sand mining. Aashik used to be involved in sand mining; however, as of the time of this interview he has been pursuing alternative livelihood options with the support of EFL. Here he talks about having the deed to land that is no longer even there, it is under water because of sand mining. 
Randev: "Changes means... a lot of damage has been done because of sand mining, it is the main thing...River banks breaks away...normally the middle of the river is dug so when the middle is dug banks on either sides break away." "It has been said to stay a certain number of kilometers from the bridge to do mining but still they do it secretly..."

Manuk: "When the water level goes high, that means during the rainy season when the water level goes high the river is not like before, now it quickly takes away whatever it can like the edges of the river. Before when the water level goes high there was not this much erosion. But now soon as the water level goes high the river tries to come in even from the smallest place."

The two previous quotes both come from men who are or have been engaging in sand mining, they are both speaking to the erosion that is brought on by sand mining. Randev is someone who was involved in sand mining, although, at the time of this interview he had moved away from the industry because of legal issues. He also mentions the concern for the bridge, it is illegal to mine within a certain distance from the bridge for fear of making it unstable, however, as he says, people still mine too close to it. Manuk is a young man who is still engaged in sand mining but he is in the process of finding an alternative source of income. He offers a description of how erosion takes place at a rapid pace because of sand mining. The river has been made deeper and deeper, so during floods the power of the water creates drastic erosion.

\section{GENERAL ENVIRONMENTAL DEGRADATION}

A number of participants talked at one point or another about the general environmental destruction caused by sand mining. For many people the most obvious environmental problem is the state of the river. For residents who have lived in the area for a number of years, it is easy for them to see how there have been significant changes to the river itself. 
Dulani: "Those days we used to go to the river, but now we are scared to go to the river because there are pits in the river and name boards and even in an emergency we do not go to the river. Anyway now there is no river now, there are just pits down the river, those pits are washed off...there is no river for our children to see..."

As Dulani points out, there have been such drastic changes to the river in recent years that they do not even go there anymore. In this one quote, she sites several concerns. On the one hand she says the river is now too dangerous, while on the other, she is concerned that her children will not be able to see the river as the beautiful place she remembers.

Annika: "That area was very beautiful, there were a lot of trees. Now because of mining the roads are also ruined. Big vehicles are scared to go on that road because they don't know when the sides will fall off. A big harm has been done. Those days we love to go there it was really beautiful. There were lotus flowers. It was a very beautiful area, Maha Oya was the only beautiful place, it was full of trees. Now it's all gone." - "Normally when we go to the middle of the river the water gets this high but now soon as we step in the water it is this high. That means they dug out sand from the beginning. When it rains the water comes straight to the road so can't even go on the road. The water is muddy."

Similar to the quote from Dulani, Annika talks about the depth of the river, this specific issue was one that came up in many interviews. In the recent past many residents would utilize the river regularly for bathing and washing, however, since sand mining has increased the river has gotten much deeper, and significantly more dangerous. While out on the river I did observe some people still using the river for washing, though conversations with interviewees would suggest that this practice has greatly decreased.

Thushara: "Now it's like this: harm to the environment should have been stopped earlier. Now the harm is done already. There were sixteen houses on the other side...I told you earlier there were sand mountains, it was washed away to the water bit by bit, after that only a court order came to remove those...Now the harm related to sand is over. There is nothing to be harmed there anymore. What is left is gravel, it will never be washed away from this side. That is what has happen. Now there is nothing."

"That is the reason. Before, this environment was good. Now the environment is destroyed. It cannot be saved in anyway." 
These two quotes are from a man who is actively involved in sand mining. First he explains that in fact there has been a great deal of changes and environmental degradation because of sand mining. The most profound part of this statement, though, is his perspective on what can be done now. The way he understands it, the environment has already been altered or even ruined, and now nothing can be done to change that, it is too late to save the environment.

Of all the people included in this study, he was the only one that had something like this to say about what has happened as a result of sand mining. Thushara, however, is looking at sand mining in a different way than most of the people who were interviewed. He has been quite successful in the sand mining business. He owns the boats and the trucks needed to transport sand and he has several people who work for him. In another part of the interview he talked about the great benefits he has received through his involvement in sand mining; it is clear that in his mind the destruction has already been done, so people may as well be allowed to continue mining.

\section{Communication about SAnd Mining in the Community}

Spending any amount of time in these three villages it is difficult to ignore the presence and prevalence of the sand mining industry. There are numerous tile and brick making factories lining the roads. There are often mounds of sand along the road or in people's yards. And if you are out on the river it is likely that you would encounter at least one boat of sand miners or a group of men working along the banks. Sand mining is so pervasive in these communities; it is simply part of everyday life. Despite the degree to which these communities are immersed in the sand mining industry, it is also 
important to explore whether or not it also commands the focus of conversation among residents. During interviews, it was surprising that many people responded that there is minimal conversation about sand mining.

Several respondents discussed a common trend in the way that people talk about sand mining. On the one hand those who are involved in sand mining tend to discuss the problems associated, for example, the water is too high, meaning they can't mine, or the potential legal issues. On the other hand those who are cognizant of the environmental destruction caused by sand mining tend to speak, though usually not openly, about the problems it causes. The following quotes from Dulani and Annika help to explain this position.

Dulani: "It is like this: people who do sand mining talk about their job, whether they have work or not. But people who don't do sand mining talk how harmful it is to the environment...two different aspects."

Annika: "Yes, they do talk a lot about it. People who are involved in sand mining talk among themselves and others also talk about it. Because there are many problems related to sand mining. I think every day they talk about it a lot.""They talk a lot about the destruction done due to sand mining, even the roads in that area are destroyed because of that."

Randev: "Generally...people who do sand mining talk about not giving permits to them. People who don't do sand mining talk about the harm cause by it, they see the harm more."

\section{SECRECY SURROUNDING SAND MINING}

An issue that came up a number of times during the interviews was that of the secrecy surrounding sand mining. Several respondents were weary to speak with us about sand mining for fear that others in the village would find out how they feel about what is happening. For most people interviewed, they held some opinions regarding sand mining, although commonly they made it clear that they did not want others to know. The most 
explicit reason for this was the fact that so many people in the village are dependent on sand mining for their livelihood. The worry for some was that they would be viewed as unkind for speaking out against the way their neighbors support their families.

Dulani: "I am scared to give an answer to this...though we are not involved, Laxmi's people are involved... if we give answers to these..." "Does she say she won't tell? No, I haven't spoken with anyone and I am not going to speak with anyone." - "If someone is in trouble, I don't care what other people do, but I do what I can to help them. Other than that I am not going to tell whether I like or dislike sand mining. It is difficult for us to stop. You could stop it because of your program. There were a lot of people in this village who did not like sand mining but they couldn't stop it. They had to stop it after you all came in. Otherwise they would have been continuing this."

These quotes come from an interview with a woman in Jambugaswatte. Several times throughout the interview she asked again for reassurance that I was not going to tell her neighbors anything that she told me. In this quote she specifically refers to a woman named Laxmi. Laxmi is another women in the village and a friend of Dulani's; Laxmi's husband is a sand miner. As of recently, Dulani and Laxmi even work together, as they are both part of Ran Liya, the women's association which formed to make shoes. The intention of this group is that the profits from making shoes will help families involved in sand mining move to another livelihood. It is clear from Dulani's response that she is worried what she says will get back to Laxmi and the other women of Ran Liya, she believes that if they knew how she felt, they would think she was speaking against their families source of income. The result of this fear has been that she simply does not share her opinions about sand mining with anyone. 
Annika: "People scold them but they don't like to say anything to their faces because people do it for a living. A lot of people who work in sand mining, are poor; people from far away places have come here to work in the mines. Sometimes people who are not involved in sand mining scold those people, but they don't say it to those people's faces because we all live in the same village and do not want them to be angry at others. So they don't say it to their faces. But otherwise they scold them some even curse them because they are digging the earth. Things like that do happen."

Annika is acknowledging that many people in the village are displeased with sand mining and how it is adversely effecting the environment. Some people may express their opinions about sand mining, although they would never say it directly to those who are doing it.

Rajeev: "No, they don't talk about it openly."

Araliya: "Some are scared to talk in an area like this. It is the main source of income for many people."

The two above quotes came from an interview with an elderly man, his daughter-in-law was present during parts of the interview and also added her thoughts at this one point. Rajeev was responding to whether or not there is talk in the village about sand mining, while Araliya was speaking to the idea of having a group specifically for talking about sand mining and the environment. Both of their responses articulate the fact that many people in the community are hesitant or even scared to be honest about how they feel about sand mining and what it is doing to the environment.

The secrecy around the topic of sand mining is an interesting aspect of this project. This is especially true because as described earlier, it is near impossible to ignore the prevalence of sand mining after spending any amount of time in these villages. Everywhere you look in the village there are constant reminders that sand mining is the main economic activity, and it is even clear that many other activities in the community 
are tied to the continuation of sand mining. While out on the river, on any day you can find sand miners working, in the water collecting sand or on the banks loading trucks. Furthermore, there are expansive pit mines along the river, which have drastically altered the landscape of the area. These features of the industry are difficult to not acknowledge, even for an outsider who has just come to the community. The fact that people tend not to express their concerns about sand mining could have the effect of deceiving sand miners into thinking that the community as a whole is supportive of the industry.

\section{ECONOMic DEPENDENCE ON SANd Mining}

One theme that came up over and over was that of the importance of sand mining for economic reasons. When respondents were asked to talk about the other income generating opportunities available in their village most were able to only site a few alternatives. Commonly, people would suggest that in the absence of sand mining people could be a day laborer, work in a tile or brick factory, or go to work in the garment factories. When looking at the garment industry, however, we see that the majority of people who work there are women, meaning that for men who are trying to move away from sand mining this is not actually a feasible option.

Aashik: "Nothing in this area. The main income in this area was sand mining. Very limited amount of people go to work in garment factories, they are girls. Many others are involved in sand mining."

Rajeev: "Income generating sources are very low. People live from clay and sand mining. Tiles and bricks are made from clay. Income is very low. Lot of people do sand mining, some in hiding, because of no other income."

In these quotes, both Aashik and Rajeev speak to the fact that for people in this community there are limited options for work. Some young girls are able to find work in the garment industry, though this option tends to come with inadequate working 
conditions and pay. Often respondents said that people could work in the brick and tile factories. However, since sand and clay form the foundation of brick and tile, this industry is completely dependent on the continuation of mining as well.

Aashik: "If talking about the people here the main thing is unemployment. That is one of the things. Also, we started sand mining for rupees three and cents fifty (Rs.3.50) far as I know it was Rs.3.50. One cube of sand was priced for about rupees eight (Rs.8.00) Earlier generations of the people who do sand mining now are the ones who started doing it long ago. Now those people are unable to do their job because of legal and environmental issues. Even today when they are asked to come for this miss's discussion they first went and unload a cube of sand and came here. Otherwise by tomorrow they are all down (broke). It is difficult even for me. It is difficult for people to be without work even for a day. There are no alternatives."

This man expands upon the extent to which the people of this village are dependent on sand mining. Aashik had been a sand miner for most of his life, though now he is in a position to move away from it because of training from EFL. In his quote he refers to a "discussion" being held; he is talking about a meeting that happened prior to this interview. The meeting was for sand miners in the community who are interested in learning about inland fishing opportunities, a livelihood EFL has been encouraging and supporting. Aashik also talks about the amount of money a person could make in sand mining, though his explanation is somewhat confusing, it is important to gather that without sand mining there is a loss of income.

Annika: "I don't know much about sand mining, but now it has become an occupation for many people. People from other areas come here to work in the mines. If there is no sand then many homes will be faced with nothing to eat because lots of people are employed in sand mining. That's about what I know, don't know much about it."

Imalka: "Lot of sand mining was done earlier, now it has decreased. What has happen from that...they don't have jobs anymore. It's difficult to work anywhere else for the sand miners. They don't get the same income from doing labor work." 
Salini: "To stop...they have to make a living so they can't stop it right? Even if we say not to do it, even if we don't like it."

Annika and Imalka are both referring to the difficulties people tend to face when they cannot continue sand mining. It is clear that many people interviewed understand sand mining as a direct link to people's ability to feed their families. While Salini speaks to the fact that simply sand mining is their job, in her perspective, it does not matter what she thinks of it, and those involved in sand mining will continue to do it until other options are available.

Thushara: "This is the only way for lot of people in this area." - "There is no other proper way of earning in this area isn't it? There is nothing in this area. Let's say we sell fish. We take fish from here and sell. When we give it for credit the next day we don't have money. Now if we dug out one cube of sand, we can manage from money in hand that's why a lot of people are involved in it. No one buy it for credit. Now let's say you have a shop that also has a credit book people bill it to credit book and take things. Sand...even outsiders will come and buy it for cash. This is why people, they get money today, no need to wait for a week or month. They put money now and get back money then and there. That's why people are involved in this."

In the previous quote Thushara is addressing the fact that even if people were to explore other income opportunities, they are not as good as sand mining. He makes an interesting point when he talks about the example of fisherman trying to sell their fish. In this village it is common to give people goods on credit, which means that a fisherman could arrive home at the end of the day without the full amount he should have earned from his fish. On the other hand, though, sand miners are always paid up front for their work, making it a more beneficial option.

It is quite clear that the communities involved in the study are highly dependent upon sand mining as their main source of income. Some respondents, though, would claim that their families were not involved in sand mining; however, upon further 
questioning it would become clear that in fact they are involved. When people say things like this, it truly serves to illustrate how entrenched the community is in sand mining, it is to such an extent that they often times it goes by unrecognized.

Chanally: "He works down there. He extracts clay. Loads sand to vans. For one sand they pay Rs. 150/- per day, he loads about three or four cubes of sand."

- "They bring sand and unload it. He loads it to the vans. My husband doesn't do sand mining."

_ "Now it rained couple of days ago and people didn't go to dig out sand because the water level in the river was too high, so my husband didn't have work."

The previous three quotes came from a woman who was talking about her husband. At first she explains that his work is to load and unload sand, though she also says he is not a sand miner. Finally, she mentions that when the sand miners are unable to work because the river is too high, her husband also does not have work. Though, she is correct, he is not a sand miner, it is clear that his income and ability to work is directly connected to the sand mining industry. The way this woman describes this serves as an indicator of the extent to which the residents of these villages are inextricably linked to the continuation of sand mining.

Thushara: "Sand mining...it's like this, here if they are not doing sand mining then for now as said before, shops, now this is the village. Most villagers are doing sand mining, if they lost their job then shop owners will also loose their job, three wheel drivers will have no hires, people will have no way of getting their medicine. If sand mining is stopped then there will be problems like that here."

This quote comes from a man who is a sand miner. He builds on the idea that the entire community is dependent on the income from sand mining by pointing out that even those not actually mining sand need it to continue. Since so many people in these villages make their income from sand mining it means that they also tend to drive all other economic 
activity. In the absence of income from sand mining many people would be unable to shop in the local shops or pay the three-wheel drivers.

\section{Legal Concerns With SAND Mining}

Due to the obvious problems associated with sand mining, the GSMB (Geological Survey and Mines Bureau) under the Mines and Minerals Act of 1992 was given full control over sand mining activities in Sri Lanka. As was described in Chapter 2, the GSMB instated a licensing system which dictates when, where, how much and who may take sand from the river. However, the GSMB is grossly lacking appropriate funding and resources to implement this type of oversight, therefore people continue to mine sand illegally. The result has been that some people have been fined or taken to court for not following the laws. For people who own boats it is difficult to find workers because people are afraid of being caught. This is exemplified in the following statement from Aashik. He is a man who owns a boat for sand mining; he has noticed that people are unwilling to work for him for fear of getting in trouble. Aashik offers this as one of the main reasons to pull away from the sand mining industry.

Aashik: "There were many reasons to stop sand mining. Legal issues came up, issues with the employees." - "When there are legal issues the people are scared to work."

These next two quotes exemplify the general perspective of many people in the community, they are well aware that sand mining is illegal in most cases. People in these villages tend to be familiar with the licensing system, and it is understood that without the proper permit you can be arrested and/or fined by the police. However, at the same time, it is also obvious that many people engage in sand mining illegally. While talking about the legal issues with sand mining though, respondents also attest to the fact that they 
know people are acting illegally. Everyone appears to know that the permit system is neither properly observed nor enforced.

Imalka's Daughter: "Now it is not allowed to do sand mining, the police will catch you."

Manuri: "Yes, in this area they do sand mining. Now it's been banned but I think they still continue to do it secretly (laughing)."

Jehan: "Sand mining is banned." "Now there are two bridges right...one with railway tracks and the other the main road...so therefore it's been said not to do sand mining on either side up to two kilometers, but some do it during the night."

\section{Social Problems Associated with SANd Mining}

Sand mining creates obvious environmental and economic dilemmas, although

there are also social problems associated with this industry. The changes created by sand mining have led many families to feel anxiety for how things will be in the future for their children. Likewise, many people in these villages have utilized the Maha Oya as a place for bathing and washing, although this is becoming less and less. As the river becomes deeper from sand mining, it also becomes more dangerous.

Dulani: "You are asking about good health? If you take sand mining, they cut trees and then that effects the environment and then we get less rain and temperature goes up. I always want my children to have a better future, I always think of my children... whether they would have a good or a bad future, nothing beyond that."

Manuri: "I think they are mining sand around the corner, no matter how many times they've been stopped they still do it. So it's inconvenient for people who go to bathe. Sometimes because of sand mining that area becomes deeper...therefore...little children go there to bathe...problems like that."

In the quote from Dulani, she is expressing concern for her children's future; she worries that her children will not have a clean environment to live in. Similarly, Manuri talks about the danger of going to the river now. The river has become much deeper due to 
sand mining, making it unsafe for many people, which is terribly inconvenient for those who have depended on the river as a place to bath and wash clothes.

Thushara: "After school in the evening I did sand mining, it started from there. Because of that my school education was also reduced. The job was good. I got money so I keep going there and keep doing it still."

Thushara talks about the fact that he began sand mining while he was still in secondary school; however, he then dropped out because he was able to make so much money sand mining. He is the only respondent who discussed this particular issue, though the literature would suggest that this is a common experience for many young men. Socially, it is valuable for communities to have students who finish their secondary education, so taking students away from school has a detrimental effect on the community as a whole.

\section{WATER RELATED ISSUES}

A clean and adequate water supply is the basis for human and environmental health; it is for this reason that this study includes an exploration on the state of the water supply in these villages. Water can be employed as an indicator of general environmental health, to that end I asked respondents to tell me about any water related problems they face. Since the interviews took place in three different villages (though all in close proximity to one another) there was variation from one to the next on the kinds of water issues they face. The village of Thoppuwa had many people who talked about not having an adequate water supply in the recent past, however for most interviewees they now have access to a tap line, which they pay for. It was unclear as to whether or not sand mining was the reason for the changing water availability; none of the respondents spoke about this. Even still, many families are without water some times and for many people it means they go to the river for water. 
Ayanthi: "We take from the tap at madam Weerasinghe's house. There is a tap we take it from that." - "yes we take water to drink from the tube well. There is water at the entrance of that pub we take from there also. That is also a tube well."

- "They did speak. They spoke, paid money, did many things and got this pipeline. Now lots of people have taken water from it." - "Water is not a problem for us now. People who has money in this area have paid and taken water from the pipes."

Ayanthi has an interesting perspective about the water situation in her village. She speaks about how the water tap lines came to their village. Those who were willing and able to pay now have access to water more readily. However, Ayanthi is not in a position to pay the fees, so she gets water from her neighbor's lines. Despite this though, she says they do not have any water problems in her community.

Manuri: "Yes, not enough. Now there is no water today, there was no water yesterday also. Metered system is used." - "Water problems do affect us here a lot. Now even if we dig a well here that water, it's not successful. That means...I spent a lot for water, earlier I took water by pumping from a motor that was also same. Now this even though we pay for water that is also a problem." -

"Sometimes they put lot of chlorine to the water. At first they didn't say anything like that. Normally it's difficult to drink chlorine water...those kinds of problems..."

"I have not seen it...I think, now see at a time like this there is no water right? So they may go to the house next door and say look we don't have water and you also don't have water. Maybe they talk about it in situations like this."

The previous quotes from Manuri offer a very interesting perspective on the water situation in this particular village. Here she is talking about the problems with water in her community, even though people have paid to receive water from the pipeline, there are still many times when they do not have water. In the second section of quotes she was speaking to whether or not people talk about water with one another. Her response to this was a common view among interviewees; people tend to talk about water only when there is a problem with it, either an insufficient amount or poor quality. 
Imalka: "Yes now the taps are all fixed. The tap is fixed on the road we have taken a pipeline from there to behind our house. But there is no water today." "Can't, it's difficult. Now today the whole day there is no water so we have to go to Maha Oya to bathe. For drinking we fill up water and keep aside." - "Now the water is sent from Maha Oya, but we filter it and take."

Imalka speaks to the fact that on the day I was interviewing, there was no water coming from the taps, a common problem for this community. When she says, "can't" she is referring to the fact that the tap does not provide enough water for their household needs. In Thoppuwa, despite having a tap line, there are still many days when families are forced to go to the river to water for their homes.

In Jambugaswatte, the other village where several interviews took place, there were fewer issues brought up concerning water problems. Most of the people in this village have a well at their home, and they receive all their water from that one source. One woman did mention that their well ran dry; they were forced to dig a much deeper well in order to reach the water table. The other main concern that people brought up was the common problem of having sediment in the water.

\section{SUPPORT FOR THE CONTINUATION OF SAND Mining}

Of all the interviews there was only one participant who explicitly expressed support for the continuation of sand mining. Though he is the only one who directly talked about feeling that sand mining was a good thing, it is still important to include his opinion. This quote comes from a man who is still highly involved in the industry, and he is someone who has benefited immensely from being part of it. In the past few years he has been able to make a significant income and even expand his business. The following quote was his response to whether or not sand mining has changed over time. The only 
changes he sites are related to improvements in his own business and how he has

benefited.

Thushara: "I didn't have a van in those days. I only dug out the sand and sell it there. Now I have a van, I can transport sand in it. Things are good for me...this happened to me."

\section{GENDER AND THE ENVIRONMENT}

As part of this study, I asked respondents to talk about whether they feel that men and women tend to have similar or different views on the environment. While many interviewees simply said that they did not see any differences, there were still some who think that men and women have varying perspectives. This is an interesting aspect of this project because the majority (if not the all) of sand miners are men, while in most cases it is women who are in a position to see how the environment is changing.

Imalka: "Yes, men think about it in another way." - "I don't know what men think, but women of course think these things are good to do for the environment...you know they talk about that." - "Now let's say we been asked to come for a meeting of some society to aware us about the environment, then they won't come, majority are the women who go for it. Maybe I think it's because men has to go to work."

Imalka speaks about how women are in a greater position to be involved in conversations about the environment. In the end of her statement she makes a point about men being less involved because they have to go to work, this was a common reason for the disparity in opinions between men and women.

Manuri: "Mostly regarding water...women are the ones who are in the household right? So women face a lot of problems." - "I think when it comes to women they are more interested in the environment don't they?"

Manuri expands on the point that Imalka made, another common sentiment that came up during the interviews. Here she talks about how women are more engaged in questions 
about the environment simply because they are the ones dealing with the problems that arise because of it. Most commonly it is the women who will need to go to the river for water or for washing when the wells do not have enough water; likewise they are the ones facing a greater danger at the river now that it is much deeper. In the following quote Nabeel also talks about why men may have a different perspective on the environment. In his view when men are off at work they have little say in what they do actually are doing. He mentions, for example that if he is at work and someone tells him to cut down a tree he will have to do it because it his job; this may be the same for sand miners.

Nabeel: "Yes miss, this issue arise because of women who are at home...to bring water, it's not use who goes. Women take, and bring water so they have to resolve this issue." - "A man means madam, now I am a labor and as a labor I have to face problems that arise daily. It's an important question. But this is why my wife told me, don't do any wrong doings and look after the children till she comes back. She went abroad to suffer. It's very important. It's very true. What women feel for the environment is very less among men." - "When I go somewhere to work if they ask me to cut this tree I have to cut it down don't I? That's why I said I'm a labor. In my daily life for me to earn something I will do that work."

\section{CONCLUSION}

Since sand mining is such a pervasive activity in these villages, most residents had something to say about it. Interestingly, though, even when participants would say they knew little about sand mining, it still would turn out that they had something to share with me. Through conversations with village residents in this manner I was able to learn a great deal about how people understand their environment and how their social structures are effecting the way they use and talk about natural resources. 


\section{Chapter 6: Participant ObServation Findings}

The following chapter presents the findings associated with being a participant observer for a period of three months. I participated closely in the operations of ELF and also spent time in the villages along the Maha Oya apart from conducting interviews with residents. As an intern for EFL my time was split between working at their office in Colombo and joining staff members on excursions to the Maha Oya project site. While at the office I was assigned various projects intended to support the mission of EFL in general and the Maha Oya project in particular. I created an informational brochure intended as an awareness-building piece- outlining sand mining and the consequences of it and the work being done by EFL. I also helped formulate a research plan, with questionnaire, for assessing the economic value of the ecosystem along the Maha Oya. The design asked information of local businesses in order to calculate the economic benefits of having a healthy environment and the economic costs to having a degraded one.

I learned a lot about the workings of the organization through my time spent in the office working on numerous aspects of the project, although it was often out in the field that I truly began to understand why this project is so important and how sand mining really affects the daily experiences of the people who live there. I was able to attend meetings with community members and leaders, such as the principal of the local school. I participated in the collecting of water quality data under the direction of a professor from a Sri Lankan university. I was able to see two alternative livelihoods shoe making and inland fishing- take shape throughout the months I was there. 
Additionally, it was extremely valuable to simply have the opportunity to spend time in the villages and interact with those who live there.

This thesis project draws not only on the data collected during interviews with residents, but also on the observations and interactions within the villages and with EFL staff. These experiences provide another level of data and information, which are valuable and should be reported along with the interview data because it leads to a broader understanding of the issues particular to this community. In order to capture my experiences in the field as data, I kept a journal, recording notes from each trip to the villages.

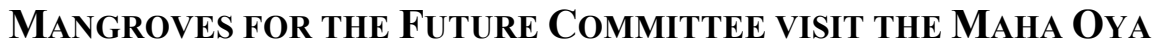

The project conducted by EFL along the Maha Oya is funded through a grant from Mangroves for the Future (MFF), a daughter organization of the International Union for the Conservation of Nature (IUCN). The main goal of MFF is to support resilience and appropriate management of coastal communities, especially those most severely effected by the tsunami of 2004. MFF offers grants for a number of small projects and fewer large projects throughout South Asia; EFL was awarded one of their larger grants to complete this project. The project was expected to take place over the course of two years. While I was working with EFL from June through September of 2010 they were coming to the end of their first year working on the project. In the beginning of August 2010 representatives of MFF came to check on the progress of their work.

The details of this meeting are important for understanding how EFL came to see where my skills as a sociologist could be utilized for our mutual benefit. Similarly, this meeting also provides a good framework for presenting the various aspects of the Maha 
Oya project. For me, the experience of being part of this day allowed me to gain a more complete perspective on how projects like this one really function. In a place like Sri Lanka, meetings with funders - such as this one with the MFF representatives—are treated as formal events. There was a distinct feeling of hierarchy in which the representatives of Mangroves for the Future were at the top and the staff of EFL underneath them. This did not seem intentional on either end; rather simply the way meetings like this operate in Sri Lanka. As an outsider, and especially a Westerner, I was surprised to see how EFL staffers appeared to be genuinely worried about impressing and pleasing the committee.

First of all the EFL staff took the committee on a boat ride down the Maha Oya. It is from this perspective that one can truly begin to see the effects and prevalence of sand mining in the area. We encountered several groups of men mining in the river and some loading trucks along the banks. It was impossible to ignore the countless coconut trees angling into the river, a sure sign of bank erosion. One of the most impressive indications of sand mining though, was in the expansive pit mines that we passed. We stopped at one where the earth had been dug at least fifteen feet down; at the bottom of the pit a pool of stagnant water had collected. Figure 6 shows this particular pit mine, one of the largest along the Maha Oya within the project area. 


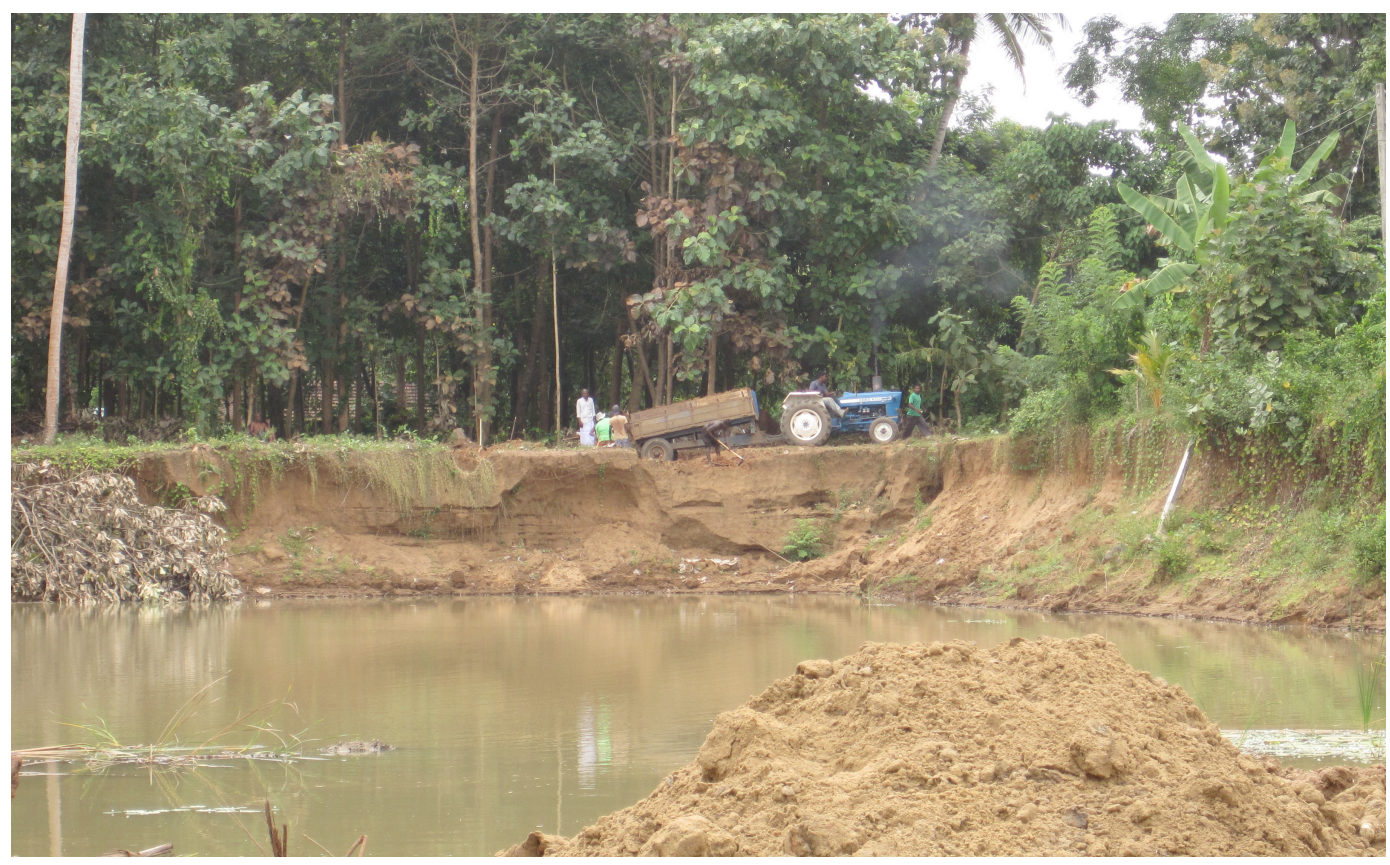

Figure 6: Pit Mine

After touring the river, we visited the place where the women of Ran Liya have their shoe manufacturing operation in Jambugaswatte. Some of us from EFL had been there just the day before, it was clear they had made significant progress in making shoes ready for sale since then. The training needed for manufacturing had been offered to anyone interested during the week of July 12, 2010, an event organized by EFL. The committee was impressed with the shoes, but they also expressed concern for the marketing that would be needed in order to create a successful and sustainable business for the women.

Next we visited the site of the inland fishing operations, another alternative livelihood promoted by EFL. There is a point in the river where it used to meander around a bend, however today that area has been mined so heavily that it more closely resembles a lake than a river. It is in this area that they have built a floating net system to 
be used for fish cultivation. MFF representatives suggested that this area could also be used for recreational purposes; although in the time I was there nothing came of this suggestion.

One of the most interesting things to come out of this meeting was the trip out to the coast about twenty kilometers (12.4 miles) north from the mouth of the Maha Oya. Coastal erosion in this area is extreme and easily apparent to all. There were a number of homes of which only ruins were left behind. Dr. Nalin Wikramanayake, of Open University, explained that entire rows of homes have already been lost to the sea. In some places the road along the coast is crumbling and in threat of being destroyed altogether. Some governmental organizations are engaged in long-term projects aimed at protecting this fragile coastline, although this is an enormous project requiring significant resources; they are only able to address the needs of several kilometers of coastline each year.

After touring all the main parts of the project area, EFL staff and the committee convened for a wrap up meeting to allow the representatives to share their comments on the progress of the project. Assembled in a large meeting room, each person was given the opportunity to reflect on what they had seen during the day. Most of the committee members commented on the fact that EFL displayed competency in collecting relevant scientific data to support their mission within the community. Many were impressed by the introduction of alternative livelihoods, but still they also voiced concerns for the sustainability of both endeavors.

For most of the representatives, they thought that EFL did not give appropriate consideration to the social dimension of what was taking place in these communities. When looking at this project from an applied sociology perspective, this aspect of the 
meeting was the most meaningful. Many of them commented on the fact that EFL had provided insufficient data when it comes to presenting a social analysis how changes in sand mining are affecting the people who depend on it. They wanted to know more about how residents actually understand the problems associated with sand mining, not only a scientific explanation. In their opinion, a social understanding would serve to make the science more powerful and more meaningful. One member of the committee stated that he would like to see case studies, which could be used to speak to the ways in which individuals are coping with the problems associated with sand mining.

Up until this meeting took place it was clear that even though EFL was supportive of what I wanted to do, they were unsure on how to use me to help their project. When the meeting came to an end however, EFL staff had explicit direction from the committee on what was missing from their project and saw that my skills as a sociologist would be useful in attaining these goals. It was precisely the kinds of questions I wanted to ask that the MFF representatives wanted answered. The committee articulately pointed out how an applied sociology project can be an asset to the larger goal of creating sustainable and resilient communities and ecosystems.

\section{Shoe Making as an Alternative Livelihood}

As a method of limiting the strain sand mining has on the environment, EFL has focused on supporting community residents who are interested in taking on alternative livelihoods. As a participant observer I was able to witness shoe making as a livelihood unfold in the community. During my first visit to the Maha Oya, we attended part of the training for shoe making. This training lasted for a week and was open to any interested villagers. The training was held at a local Buddhist temple, one that has been consistently 
supportive to efforts of EFL. On the day that we visited there were about twenty people there, mostly women all learning this new skill. Figure 7 shows some of the women during the training event at the local temple; also shown are some finished shoes made by Ran Liya - the women's association, which was formed after the training event.

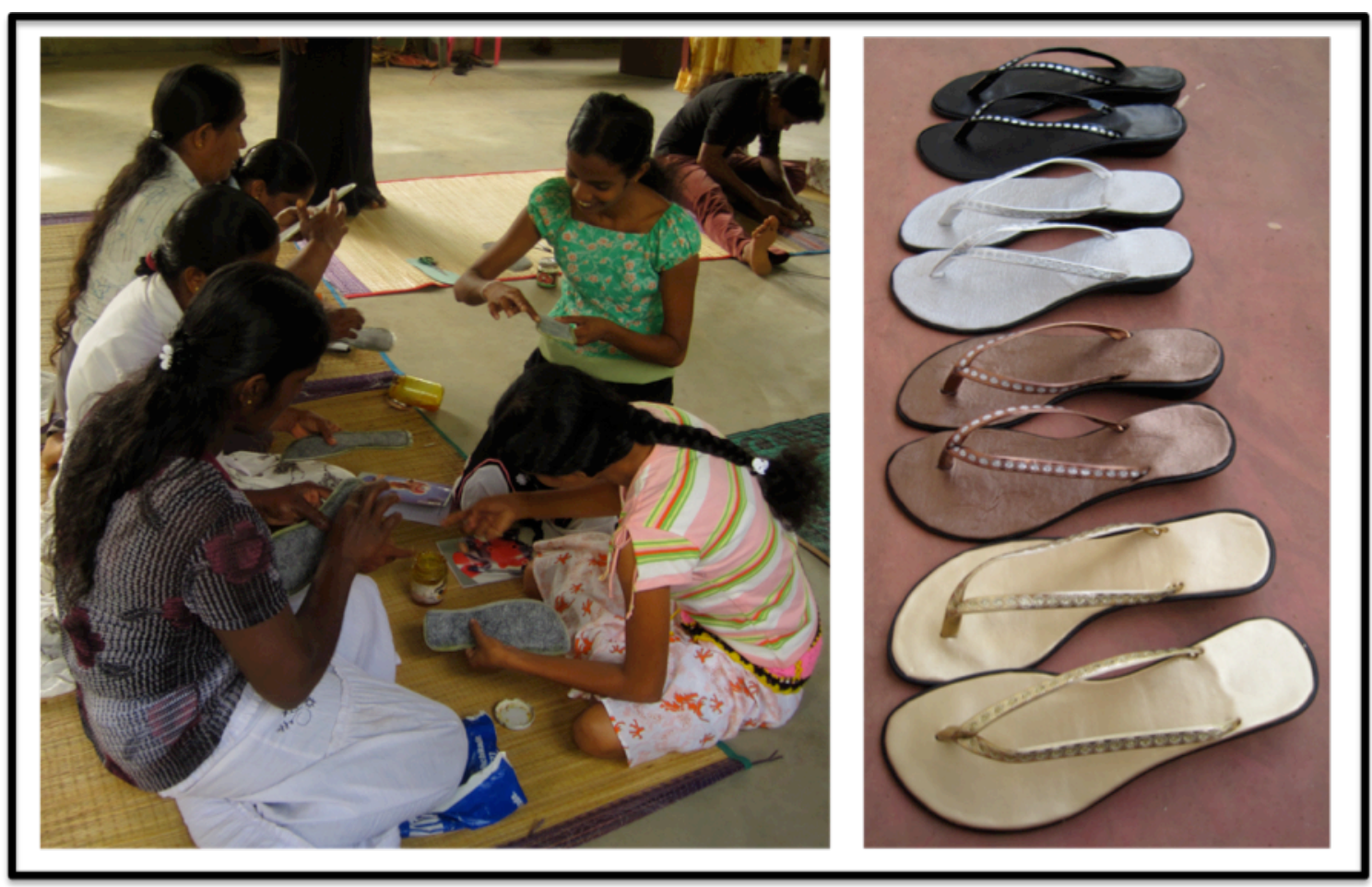

Figure 7: Shoe Making Training \& Shoes

Some of the women who attended the training are the same ones who formed Ran Liya, an association whose main goal has been to support each other in making shoes to sell in town. On July 27, 2010 Priyanka and I attended a meeting with the women of Ran Liya; twelve women were in attendance. Though Ran Liya was not formed by EFL, Priyanka served as a resource and guide to the women. The main agenda was to discuss how they could utilize their shoe making skills to generate income. An important element 
of discussion was the existence of competition from another group. However, they concluded that their shoes would be better quality but also more expensive to manufacture. The women decided that it would be important to publicize the fact that their shoes may cost more, but also they will last longer. In addition, during the meeting they made a plan with Priyanka to come to Colombo to buy the supplies necessary to get started.

After attending this meeting, every visit to the Maha Oya included a stop to see the women of Ran Liya. They had set up their operations at the home of one of the women, somewhat playfully referring to it as the shoe factory. From the beginning, the women appeared to be comfortable with Priyanka, and upon each meeting they became more and more comfortable with me too. It was impressive to see the progress they made each week, not only were they building a stock of finished shoes, but they were also getting better and better. Priyanka often spoke with the women of Ran Liya about where and how they could get their shoes to potential buyers, she served as an adviser to the women and helped them with the logistics of creating a sustainable business from the venture.

The women who have gotten involved in shoe making seem to be happy to have this new trade. However, since it is women who are doing this, and mostly men who are sand miners, it may not be the most effective way of limiting dependence on sand mining. The idea is that if the wives of sand miners had work then it would allow for them to find alternative ways of making a living. EFL has also worked on introducing inland fishing as a livelihood and this has been targeted mostly at men, although, while I was there, this was still very small. In order for this approach to be effective, it is 
important that there be a greater focus on alternative livelihoods that are directed specifically at men in the sand mining industry.

\section{Environmental and Social Effects of Sand Mining on the Coastline}

River sand mining causes significant erosion on the coastline. When sand is extracted from the riverbed faster than the natural replenishment rate it means that the river is no longer carrying its full supply of sediment. It is this sediment that is necessary to replenish coastal beaches, protecting them from natural erosion (Kondolf 1997).

However, it was not until traveling out to the coast that I fully understood the impacts of sand mining on the coastline.

On the day of the meeting with the MFF representatives, on August 5, 2010, while we were out on the coast I saw the road already being slowly destroyed by the crashing waves. It was easy to see the threat of erosion, though it was through a conversation with Tiran, another EFL staff member that I began to fully understand how coastal erosion is affecting the lives of the people who live there. Tiran explained that he had stood in the same place in January and taken a picture of the coastline. At that time, the water was crashing at a pile of rubble (what used to be a home), further inland there was another home and then finally a road. In August however, the water was coming up to the road and the ocean was already swallowing pieces of asphalt. Figure 8 shows both Tiran's picture from January and mine from August, in only seven months the difference is drastic. 


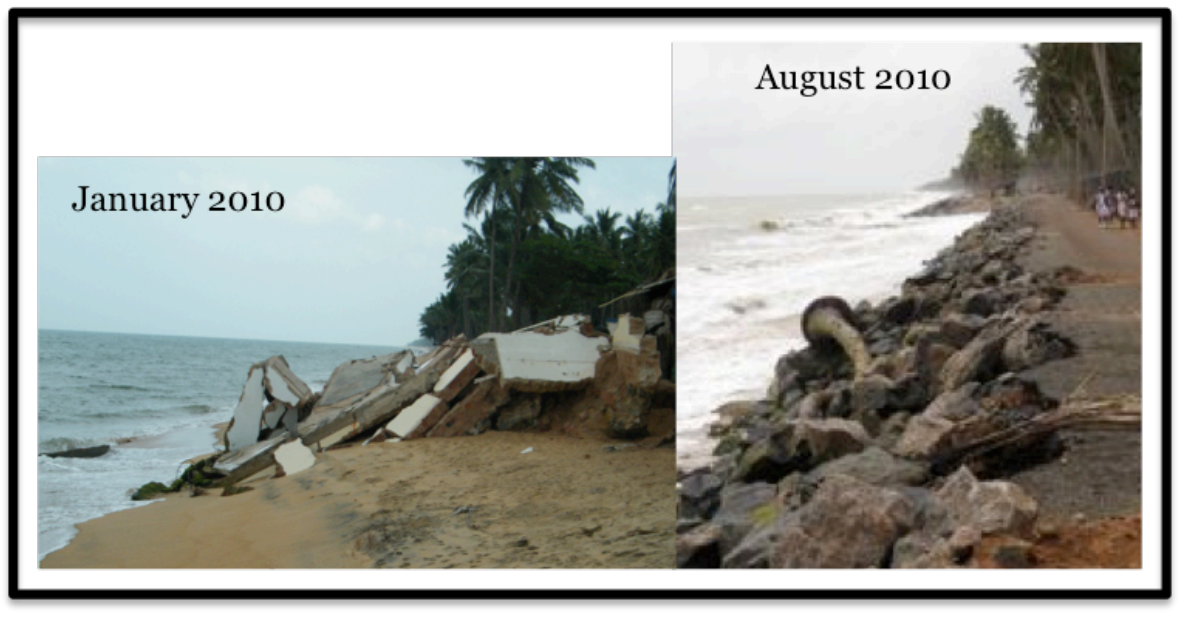

Figure 8: Coastal Erosion

As we drove down this road, with the ocean on one side and a fence on the other, the devastating effects of sand mining were all too clear. Families had been forced to leave their homes as the ocean destroyed them. However, for most of them with few resources to facilitate moving elsewhere. So, along the fence on the other side of the road many families had made attempts to rebuild a shelter out of whatever materials they were able to save from their crumbling homes. Still, though, they had only managed to move inland about fifty feet, and at the current rate of erosion, they will surely be forced to leave these makeshift homes as well.

Throughout the course of conducting interviews within the communities along the Maha Oya, no one talked about the coastal erosion. These overwhelming effects of sand mining are out of view of the people who are most directly involved in it. However, the experience for people on the coast is one that exemplifies the scope of the destruction caused by sand mining. 


\section{Collecting Water Data on the Maha Oya}

On my first day going to the Maha Oya, I was able to help collect data on the quality of water both in the river and in wells along the river. On this day, a professor from the Institute of Fundamental Studies and four of her students joined us and led the data collection process. Our first stop on the river was to pick up one more person; a man who EFL was hiring for the day to do the physical collection of necessary water samples. As we boated along the river we stopped at pre-determined points to collect samples, take water temperature and salinity levels. At each point the hired man would swim down to the bottom of the river and fill a small bottle with water from the deepest point of the river.

While traveling along the river we witnessed a number of people engaged in sand mining. Sometimes the men would wave and talk with us, while others would flee the river when they saw us coming. One time, we could see only a flurry of splashing further up the river; it was a group of men frantically swimming to get onto the banks and out of our view. The assumption at this point would be that those who do not want to be seen engaging in sand mining are the ones doing it illegally. However, I do not think it is necessarily accurate to also assume that those who did not flee are engaged in only legal activities. This particular view of sand mining is one of the aspects that make it so confusing to understand. So many people are participating in it, and in a variety of ways. It is so hard to determine who is following the laws all the time, only some of the time, or not at all.

As we passed one group of men working, we asked the diver of the group to gather the water sample for us; he gladly agreed to help us with this request. I was quite 
surprised by this. On the one hand we were seeing some men take off the moment they saw us coming, while others were happy to help us collect our samples. This encounter exemplified the diversity of perspectives among sand miners.

\section{A Space to Talk about Sand Mining}

Throughout the time I spent in the villages along the Maha Oya, including during interviews, it became obvious that people did not want to talk openly about their opinions on sand mining. Through this observation I came to understand that one of the most important roles EFL could fill would be to create a safe space for people to talk openly about their opinions. Also, in a setting like this it could be possible for community members to brainstorm solutions and management approaches that would be most appropriate for this particular community. Likewise, meetings like this can increase feelings of empowerment among residents, an element likely to facilitate commitment to the project. This idea is confirmed by the work of Elinor Ostrom (2010) in which she notes the importance of maintaining resource users at the center of management solutions. Similarly, Ostrom (2010) advocates for self-governance of natural resource use, a situation that requires open communication among the various stake holders. More about the secrecy surrounding sand mining will be addressed in the discussion chapter.

\section{CONCLUSION}

The time spent in the villages along the Maha Oya, aside from conducting interviews, was extremely valuable to gathering a full perspective of the social consequences of sand mining. Because I was around more than just to do interviews I was able to spend time with the women of Ran Liya, and watch their undertaking evolve throughout the three months I was in Sri Lanka. One of the main themes to come out of 
the interviews was the extent to which residents were reluctant to be open about their opinions on sand mining. Because of the time I spent in the villages apart from conducting interviews I was able to understand the full degree of this secrecy. For example, I witnessed some women who spend most of their days together, although even for them, they keep their opinions on sand mining to themselves.

In addition, I was fortunate to get to witness the meeting with the MFF representatives, an experience that was indispensable in gaining a better understanding of the Maha Oya project as well as EFL coming to see how a sociologist could be used most effectively. It was through being a part of this meeting that this project was able to take on its true applied nature. I was able to hear first hand what was expected of the project and the committee offered validation for the direction I had planned to go with the interviews.

It was during this same day that it became clear to me how devastating sand mining is to the coastline, something I would not have truly understood without being there. Throughout the interviews respondents were often able to point to a number of environmental problems associated with sand mining. However, none of them commented on the extreme coastal erosion. Having the opportunity to visit the coast brought this to my attention, once again offering me a more complete view of the situation on the Maha Oya.

In a study like this one, it is vital to spend enough time in the community in order to gain a holistic view of what is really happening and what it is like for the people who live there. A lot can be learned through observation, which could have been lost in conversation. Additionally, time spent in the villages was vital to me achieving rapport 
with community members; ultimately making people feel more comfortable to talk with me. 


\section{ChaPter 7: Discussion}

Environmental sociology provides a framework for evaluating and understanding the current conflicts between the sand mining industry and the communities that depend on this ecosystem for survival. As discussed in Chapter three environmental sociologists are dedicated to understanding how humans recognize and deal with current environmental problems. In order to address the ways in which the environment affects social systems, and vice versa the first step is to formulate a picture of how these interconnected systems are understood.

The residents of the villages along the Maha Oya have first-hand knowledge and an intimate perception of the sand mining industry. Everyday life in these villages is centered on the river and the sand it provides. Understanding their particular perspective is the main goal of this thesis project as well as the first step in addressing long-term sustainability. As environmental sociologists it is important that we understand the value of going directly to the source to assess the problem; this framework provides a justification for this study and the methods employed here.

\section{The Paradox on the Maha Oya}

Generally, it is important to appreciate the intense connections between social structures and the environment. Society needs a healthy environment in order to be sustainable. Particularly, though, in rural villages, such as the ones included in this study, the connections between humans and ecosystem are even more pronounced.

Environmental concerns and societal structures cannot be divorced from each other. Despite these inherent connections, there is still a distinct conflict between environmental health and social sustainability. 
The situation along the Maha Oya presents a paradox, as there are two aspects of survival, in direct conflict with one another. Promoting conservation and the limitation of sand mining will lead to many people being out of work; while not promoting environmental sustainability jeopardizes the health of the community as a whole. As many participants pointed out in their interviews, simply putting a stop to sand mining is not a viable option. The well being of too many families is wrapped up in the continuation of a thriving sand mining industry, thus presenting a challenging situation.

When looking at circumstances such as this one, it is useful to refer back to the debate between the human exemptionalist paradigm and the new ecological paradigm (Dunlap and Marshall 2007). The human exemptionalist paradigm proposes that humans will be able to relieve themselves from the constraints of the natural environment through their superior technology and culture. Sociologists, however, have critiqued this as being a far too simplistic way of addressing the problem, and the experience on the Maha Oya is no different. The humans that live along the river are feeling the intense effects of exploiting their ecosystem beyond sustainability, and the way forward will have to be drastic change in order to avoid the breakdown of natural and social structures.

In contrast to the human exemptionalist paradigm, the new ecological paradigm as described by Catton and Dunlap suggests that despite the particular technological capacity of human society, humans are still subject to the constraints of the environment. Likewise, even with extensive human knowledge, the natural environment is made of complex interconnected systems, making it highly difficult to predict potential environmental problems. The people who live in the villages along the Maha Oya could not have predicted all the possible problems associated with the over-exploitation of sand 
from the river. Likewise, technological advances of humans are not enough to alleviate the pressures and constraints of the natural environment.

In the study of environmental sociology there are two common ways of understanding motivations for sustainability, the ecocentric view and the anthropocentric view. Comprehensive sustainability, however, will most likely come from the merging of these two understandings; it is critical to protect natural ecosystems for their intrinsic value as well as for the valuable resources provided.

On the ecocentric side, many people who were interviewed reported a desire to see the health of the river restored for the sake of the river itself. Often people talked about wanting the Maha Oya to be a healthy and beautiful place for their children and other future generations. Simultaneously, though, respondents understand that the riverand ecosystem in general-provides a number of necessary resources to the surrounding communities, an aspect that cannot be overlooked. Through conversation with respondents it became clear that trying to separate these two motivations for sustainability is not appropriate, or even possible. Participants do not view these as two opposing value systems, but ones that are interconnected and both important rationales for the promotion of a new way forward.

\section{COMMUNITIES AND CONSERVATION}

It is common that rural communities are seen in opposition to conservation efforts. As Agrawal and Gibson (1999) point out, there is a sense that the goals of local communities and conservationists are contradictory of each other because communities need the resources provided by ecosystems for survival. However, as is seen in this example on the Maha Oya, many residents are interested in envisioning a system in 
which conservation is important but also one that allows for residents to have economic opportunities.

The problem is evident in the fact that many respondents were fearful to express their true opinions when it comes to sand mining, it is almost as if they too believe that conservation cannot be at the forefront of discussion. Since so many residents appear to feel this way, though, the outcome is that no one is even looking for a solution that encompasses the economic and environmental needs of the community.

\section{How do Village RESidents Understand THEIR ENVIRONMENT}

Village residents tended to see their environment for the resources it provides to them, for example, food, water and materials for shelter. Many respondents talked about the water situation in their villages, and their perspective on this was particularly interesting. Respondents would often tell me about water shortages or having poor water quality, and I would assume that these issues would be understood as problems. However, while they would tell me about the inadequacies in the water they would then say it is manageable at the same time. The words they would use to talk about water related issues would sound like problems to me, but then they would simply say there are no (or few) problems. Hearing these things simultaneously says a lot about what is normal, or expected in this community. When the norm is a poor water supply, it would be hard to articulate what the problems are; it is simply the way life is.

\section{COMMUNICATION}

In rural communities such as the ones included in this study, neighbors tend to be highly involved in each other's lives and maintain strong relationships between them. Since this is the case, it is interesting how little conversation there actually is concerning 
sand mining. Sand mining is so pervasive that it is almost as if it does not need to be talked about, it is just too obvious. Nevertheless, what conversation does take place is likely to fall into one of two contexts. For people involved in sand mining, the majority of talk centers on the hindrances to the industry. While for those who are not involved, the conversation is more about the environmental problems associated with sand mining.

Another major theme that came out during the interviews was the fact that most people not involved in sand mining did have some opinion about what was going on in the river. And if they had anything negative to say about it, they did not want anyone else in the village to know. It became obvious that this was mostly because they held a great deal of respect for their neighbors, and if people knew how they felt about sand mining, it might appear that they are unsupportive of them and their way of life. This was even true for at least one woman who was adamant about not allowing her friend to know what she said. On the one hand they know that many of their neighbors are dependent on the income they receive from sand mining; however they were also able to articulate the environmental problems associated with the industry. Being able to see both these sides puts them in a particularly difficult position, while also exemplifying the intense complexity of this issue. Generally, it was the respondents who were most readily aware of the environmental and social problems connected to sand mining that were also the ones who wanted to keep their opinions most secretive.

Another element of life in these small communities was the extent to which residents are immensely respectful and concerned for the well being of their neighbors; a fact made evident by their desire to keep their opinions on sand mining secretive. However, there are two dimensions of concern, both of which are relevant here. On the 
one hand people tended to worry about people's ability to make a living when so much of the economy is centered on sand mining. On the other hand, though, respondents also tended to be concerned for the health of the river in particular and the ecosystem in general. There is a very real economic threat to many families if sand mining were to be stopped. Despite the fact that these two ideals are in direct conflict with one another, it does not exclude them from feeling and expressing them both at the same time.

Concern for the health of the environment for the community

\section{DOSE THE TRAGEDY OF THE COMMONS APPLY?}

In Hardin's (1968) assessment of how common, unregulated resources will be exploited he proposes that individuals are essentially encouraged to take advantage of the circumstances by taking more than their share. It is thought to be an easy assessment to make because the costs of taking too much are shared among the entire community, relieving the individuals to feel less of the burden. There are however, a number of reasons why this understanding of the situation is far too elementary. After speaking directly with residents along the Maha Oya, it quickly became clear that as individuals, they are concerned for the well being of their neighbors. The fact that residents are highly concerned for how their actions will affect the community serves to void Hardin's notion of how resources will be exploited. Hardin also tends to make the assumption that individuals in difficult resource management situations have no agency or responsibility to elicit changes. Additionally, this way of understanding what is going on serves to maintain resource users as entities trapped within their current situation, incapable of creating change (Ostrom 2010). 
When posing the question of what would happen if all sand mining were stopped on the Maha Oya, many people mentioned that for many people it would translate to a difficulty in feeding their families. Similarly, Hardin's theory does not take into consideration the economic needs of natural resource extraction; with so few other options for work the income from sand mining is a form of survival.

In order to avoid the tragedy, Hardin calls for coercive top-down control over resources, essentially just limiting people's access to a particular resource. He suggests a system that would take power away from community groups and put it in the hands of those who have little connection or understanding of it. In Sri Lanka a system such as he describes has been put in place, although it has been less than successful in limiting destruction to the Maha Oya. In fact, since few people actually follow the laws, it has essentially made the resource more open-access. During many interviews, respondents mentioned that there are rules about mining, but people do it illegally. Interestingly, though, it was also clear that most residents are confused about the rules of use actually are.

The licensing system under the GSMB is so confusing that even those involved in sand mining do not understand what they are allowed to do. This again has led to people feeling like they can just do what they want. Likewise, as one respondent talked about, he was arrested for mining illegally, however, he was working for someone else and that person did not get in trouble.

It is apparent that there is a disconnection between those writing and attempting to enforce the laws and the people who are actually affected by the laws. This is a perfect opportunity for a community-based participatory system that takes the knowledge and 
desires of the local community as the bases for management. This type of management is an appropriate way forward because the people that live in these villages are completely invested in the sustainability of their ecosystem, but also they are in the best position to understand what is at stake if sand mining is simply banned or limited. Similarly, when a management system originates on the community level, those who are intended to follow it are likely to be more invested in its success.

\section{Application of this Study to the Greater Project}

Setting this thesis project apart from many others is the fact that it is an applied project. I worked closely with EFL at every stage of the research; and the data collected through interviews was immediately passed onto EFL in the form of recommendations for how to improve the overall project along the Maha Oya. In Chapter II, I refer to the social scientist Michael Cernea (2002) who suggests that including sociologists to a greater degree at more stages of social projects is vital to their success. My position with EFL was directly in line with this important suggestion. Based on the in-depth interviews in the villages along the Maha Oya I came up with a number of recommendations for EFL to take into account throughout the course of their project; some of those recommendations are presented here.

One of the most obvious areas that should be addressed by EFL is the secrecy surrounding sand mining. There is so little conversation about what is going on, which has led to most people not even knowing that there are others who feel the same as they do. Since no one talks about it, it is easy to assume that they are alone in their perspective. It would be invaluable for EFL to put energy into creating a space that is safe for people to talk openly about how they feel. Throughout the interviews respondents 
often mentioned that they thought a space like this would be useful for their community. As more people come to see that they are not alone in their opinions it could allow for more honest discussion of these important issues. It is clear that there is a segment of the population that is not being heard because those most opposed to sand mining are also the ones who remain most silent about the subject.

It is vital that those highly involved in sand mining are brought into this discussion as well, which means that all stake holders would need to be willing to hear the other's perspectives. As one sand miner told me, he would be willing to talk openly about sand mining as long as it was not simply an opportunity for people to try to stop him from continuing his work. There are a number of different stakeholders involved in this issue -from sand miners, to village residents, to construction day laborer and even state and local government officials- in order to address this complex situation. It is crucial that the various parties have an opportunity to come to a collective solution.

In order for this community to see the adoption of comprehensive environmental and socially sustainable programs first there needs to be wide spread support among the various stakeholders. The first step to gaining this kind of support is the introduction of programs focused on awareness. It was common to hear respondents talk about environmental issues in their communities, although, often they were unclear on the true connections between what they were experiencing and sand mining. Community residents need to be able to easily make the direct connection from sand mining to erosion, from erosion to a falling water table. Conversations such as these ones need to be accessible to all community residents. 
During the interviews, it was in talking with the two youngest respondents that I received the most articulate explanations about particular environmental problems. After hearing this it would make sense that programs aimed at school aged children would be a vital place to incite this discussion.

Another important element for EFL to address in their work is to be more transparent about why they are there and what their intentions are. There were a number of people who I talked with who were aware that EFL was working in the community, they might know it had something to do with sand mining or alternative livelihoods, but generally they were unable to articulate what their mission really is, or why they are there. Simply spending time in the villages and talking with people about what they are doing would likely go a long way to gaining support and understanding.

Along with greater awareness on the mission of EFL, I think it would be valuable to create a local committee to work closely with. This committee could be the first step in getting the conversation about sustainability going. It has been proven that coercive topdown methods of management are ineffective, and these communities are in a prime position to envision a new way forward where there is representation from all the local stakeholders. Village residents are the ones most closely connected to this natural resources and the most dependent on it for environmental and economic survival, thus it would stand to reason that they are also the ones in the best position to construct a truly sustainable method for managing the Maha Oya.

For EFL, their main goal is the preservation of the natural environment, and they are truly dedicated to this as well as to the resiliency of the community as a whole. However, it seems apparent that they are coming at the problems with sand mining and 
these complex interactions between the social and environmental with the intention of imposing solutions. Although, EFL is a Sri Lankan organization, the staff all live in Colombo and because of this they maintain an urban perspective on this rural community, and like myself, they too are outsiders. Coming to see how unaware community residents are about why and what EFL is doing truly highlights the lack of transparency and participation from village residents.

I believe that EFL is invested in the well being of the communities they are working with, so there could be a number of reasons why they are not more dedicated to participatory approaches. For one, they maybe simply unaware they too are imposing solutions on village residents. Additionally, after spending time in the villages with EFL staff, it is obvious that they are treated as though they have come from the city with answers and resolutions to their problems. Both staff and community residents seem to support this relationship. However, it is EFL who should be focused on breaking down this idea and working towards empowering the community to address social and environmental sustainability.

Top-down resource management solutions are rarely effective in situations like this one; as we have seen, oversight from the GSMB has not served to minimize the destruction of the Maha Oya. EFL, however, may not being doing much better as they address the situation on the Maha Oya from an urban and outsider perspective. It seems clear that they are in fact concerned for the future of this community and environment, although to really be supportive it will be necessary for them to modify their approach to a role of facilitating and encouraging participatory management. The licensing system under the GSMB does not work, partially because there is no one physically present 
monitoring usage; and EFL will not be there forever pushing for alternative livelihoods and collecting water data. The community will be there, they are the ones living with the resource and in the best position to manage it now and in the future. What happens on the Maha Oya directly affects the everyday lives of all village residents; likewise, they are the ones whose lives will change as new management techniques are put in place. Thus it is vital that residents be the driving force effecting the changes in their own community.

\section{CONCLUSION}

As was discussed in Chapter III, the goal of environmental sociologists is to ask questions in order to understand how people understand and recognize the environmental problems of their surroundings. One of the main themes to come out of the interviews and participant observation was the fact that along the Maha Oya, most people do not want to talk about sand mining in an open way. However, it will be through open and honest communication about what is taking place that widespread sustainable management can be established. To reiterate the thoughts of Heinrichs and Gross "the focus has been broadened from preserving the environment in its current status towards proactively shaping environment-society-configurations within the guiding vision of sustainable development" (Heinrichs and Gross 2010:5). The current state of the Maha Oya presents an opportunity to move forward in an innovative manner that is focused on long-term sustainability environmentally, socially and economically. 


\section{Chapter 8: CONClusion}

The issues at the heart of this project are multidimensional and often contradicting. The foremost goal here is to gain an appreciation for how the people who live along the Maha Oya understand sand mining and its effects. In the end, the village residents tend to maintain a variety of complex perceptions of sand mining in their community. However, there are some themes that stood out time and again as the most common. For one, there is a distinct sense of economic dependence when it comes to sand mining, as many aspects of life are connected in one way or another to the industry. Because of this strong dependence, village residents are also inclined toward having contradicting feelings when it comes to sand mining, simultaneously understanding the problems and also the necessity. Finally, for many residents, they are entirely secretive about their own opinions when it comes to sand mining.

\section{DEPENDENCY}

For the people who live and work along the Maha Oya and interact with the sand mining industry on a daily basis there are a number of sentiments that seem to be common. Many respondents spoke about the extent to which their community is dependent upon sand mining. With so many aspects of everyday life directly connected to sand mining, it is hard to see how life in the village could operate without sand mining at its center. Interestingly, the influence of sand mining is so pervasive that some respondents claimed to have no connection to it, but then upon further discussion it would become clear that in fact their livelihood is in someway dependent on the continuation of sand mining. As some respondents pointed out, even for those whose business is truly disconnected from sand mining, such as shop owners, they are still 
reliant on the continued income of others in the community. Sand mining drives the majority of economic activity within the village.

\section{CONTRADICTING VALUES}

After interviewing residents of the villages along the Maha Oya, one thing that became visible was the fact that for most people there was not an easy answer to the questions posed. Many respondents appeared to be dealing with an internal conflict surrounding the topic of sand mining. For one, many people are not blind to the environmental effects of sand mining, and they see these changes as detrimental. However, they also understand the intense need that they and their neighbors have for the income associated with continued sand mining. These two values operate in direct conflict to one another, and the struggle is evident.

\section{SECRECY}

Despite the ubiquitous presence of sand mining, community residents also maintain secrecy when it comes to their true feelings and opinions about the industry. During several interviews respondents checked to be sure their answers would not be shared with other members of their community. It became clear that people feared that if their true feelings were known, it would appear as though they were unsupportive of their neighbors' livelihoods. The lack of honest conversation around the effects of sand mining and also possible solutions is likely one of the most significant deterrents to a solution that is environmentally and economically sustainable. It is vital that community members reach a point at which they can honestly talk about what is happening in their villages, and how they would like to see things change. 


\section{FUTURE RESEARCH}

After completing this project it is easy to see where future research could be beneficial to gaining a more comprehensive picture of the particular issues at hand. For example, though I attempted to interview more men directly involved in sand mining, this was a population who was difficult to include. It became clear that often they were simply too nervous to speak with me. If more research was to be done, I would suggest sampling for sand miners. It may even be useful to conduct some focus groups with sand miners; in a setting like this they would be able to openly talk about their dependency on the industry and also the problems that arise because of it. Also, I think it would be useful to have more interviews with community leaders. Though, for many leaders, they are less directly effected by the environmental consequences of sand mining, it would be helpful to have a complete understanding of their perspective, as they are the ones usually holding the greatest amount of community power and influence.

Throughout conducting interviews with Priyanka, she often mentioned how useful these interviews would be to the work EFL was doing. She and I spoke to me about how often EFL staff would assume that village residents had a clear idea of the ecological concerns associated with sand mining. However, through conversations it would come to light that was not always the case. Without having a firm knowledge of how communities understand what is happening in their villages it is extremely difficult to direct intervention and educational efforts. It was through these conversations with Priyanka that I came to truly see how these interviews would be used to directly influence the situation of the people being interviewed. 
As humans, we are still at the mercy of the ecological constraints of our environment; however, with complex social systems also at play, a great need exists for the work of environmental sociologists. This example on the Maha Oya outlines the various elements that must be taken into consideration. First and foremost, though, it is vital to understand each situation from the perspective of those most closely affected by and those affecting the conditions; and this is the intention at the heart of this project. This notion is one supported by the work of Ostrom (2010) as well. She notes that rarely are top-down coercive management methods effective, and advocates for keeping communities as the driving force in sustainable governance over common resources. Likewise, at one point during this research, I was told that one of the greatest predictors of successful sustainable management solutions is whether or not village residents can see themselves in the solution. When it is all said in done, people need to understand how their lives will change and what it will mean for them. In the end, despite the fact that the questions of this project center on the environment, it is the lives and experiences of village residents that are at the core of change and sustainability. 


\section{REFERENCES}

Agrawal, Arun, and Clark C. Gibson. 1999. "Enchantment and Disenchantment: The Role of Community in Natural Resource Conservation." World Development 27:629-649.

Athukorala, Kusum, and Champa M. Navaratne. 2008. "Shifting Sands in Sri Lanka: Mobilizing and Networking for Collective Action by River Sand Mining affected Communities." in The 12th Biennial Conference of the International Association for the Study of Commons. Cheltenham, UK http://iasc2008.glos.ac.uk/conference\%20papers/papers/A/ (Accessed November $18,2010)$.

Ballet, Jérôme, Nicolas Sirven, and Mélanie Requiers-Desjardins. 2007. "Social Capital and Natural Resource Management." The Journal of Environment \& Development $16: 355-374$

Bell, Michael Mayerfeld. 2004. An Invitation to Environmental Sociology. Second Edition. Thousand Oaks, CA: Pine Forge Press.

Bibbington, Anthony. 2006. "Michael Cernea." Pp. 67-73 in Fifty Key Thinkers on Development, edited by David Simon. London: Routledge.

Cernea, Michael. 2002. "Development of Applied Social Science - The World Bank Experience." Pp. 53-78 in Starting in the Twenty-First Century: Sociological Reflections \& Challenges, edited by Ernest Krausz and Gitta Tulea. New Brunswick, NJ: Transaction Publishers.

Charmaz, Kathy. 2006. Constructing grounded theory: A practical guide through qualitative analysis. Thousand Oaks, CA: SAGE Publications Ltd. 
Coleman, James. 1988. "Social Capital in the Creation of Human Capital." American Journal of Sociology 94:S95.

Department of Census and Statistics. 2001. Population by ethnic group and district, Census 1981, 2001. Colombo, Sri Lanka http://www.statistics.gov.lk/abstract2009/chapters/Chap2/AB2-11.pdf (Accessed November 16, 2010).

Dietz, Thomas, Nives Doliak, Elinor Ostrom, and Paul Stern. 2002. "The Drama of the Commons." Pp. 3-35 in The Drama of the Commons, edited by Elinor Ostrom and National Research Council (U.S.). Committee on the Human Dimensions of Global Change. Washington DC: National Academy Press.

Dunlap, Riley E. 2002. "Paradigm, Theories and Environmental Sociology.” Pp. 329-350 in Sociological Theory and the Environment: Classical Foundations, Contemporary Insights. Lanham, MD: Rowman \& Littlefield.

Dunlap, Riley E., and Brent K. Marshall. 2007. “Environmental Sociology.” Pp. 329-340 in 21st Century Sociology: A Reference Handbook, vol. 2. Thousand Oaks, CA: Sage Publications.

Environmental Foundation Ltd. 2006. Your Environmental Rights and Responsibilities: A Handbook for Sri Lanka. Colombo, Sri Lanka: Environmental Foundation Ltd. Environmental Foundation Ltd. 2009. "Proposal Summary Sheet: Increasing the resilience of coastal and riverine communities to climate change and other threats, by conserving the ecosystem of the Maha Oya and associated coastal wetlands in Sri Lanka..” (Accessed June 5, 2010).

Fernando, K. M. N. S. n.d. "Maha Oya (River) \& River Basin from National Drinking 
Water \& Sanitation Service Providers Perspective.”

http://www.google.com/url?sa=t\&source=web\&cd=1\&ved=0CBoQFjAA\&url=ht tp\%3A\%2F\%2Fwww.adb.org\%2FWater\%2Fnarbo\%2F2005\%2FTrainingProgram\%2Fpres-Fernando-NARBOtraining.pdf\&rct=j\&q=MAHA $\% 20$ OYA $\% 20$ (River)\%20\%26\%20RIVER\%20BA SIN\%20\%20FROM\%20NATIONAL\%20DRINKING\%20WATER\%20\%20\%26 \%20SANITATION\%20SERVICE\%20PROVIDERS\%20\%20PERSPECTIVE\%2 0\&ei=SXnkTIqZHIf6sAPZiaVm\&usg=AFQjCNFC0YQP3z6H1zFjQJvintwbK9 R1Pw\&sig2=6pyDyv7fLDpq-p-8-fkvrQ\&cad=rja (Accessed July 2, 2010).

Geological Survey and Mines Bureau. 2010. "Licenses \& Procedures." Geological Survey and Mines Bureau. http://www.gsmb.gov.lk/web/index.php?option=com_content\&view=article\&id= 100\&Itemid=68\&lang=en (Accessed November 18, 2010).

Guest, Greg, Arwen Bunce, and Laura Johnson. 2006. "How Many Interviews Are Enough?: An Experiment with Data Saturation and Variability." Field Methods 18:59-82.

Gunaratne, L. H. P., and K. A. S. P. Jayasooriya. n.d. "River Sand Mining in Sri Lanka: Trade-off between Private Profitability and Environmental Costs.”. Hardin, Garrett. 1968. "The tragedy of the commons. The population problem has no technical solution; it requires a fundamental extension in morality." Science (New York, NY) 162:1243.

Harper, Charles L. 2008. Environment and Society: Human Perspectives on Environmental Issues. Fourth Edition. Upper Saddle RIver, New Jersey: Pearson 
Prentice Hall.

Heinrichs, Harald, and Matthias Gross. 2010. "Introduction: New Trends and Interdisciplinary Challenges in Environmental Sociology.” Pp. 1-16 in Environmental Sociology: European Perspectives and Interdisciplinary Challenges. Dordrecht, The Netherlands: Springer.

Jayawardena, U., and DMS Dissanayake. 2006. "Use of quarry dust instead of river sand for future constructions in Sri Lanka." The Geological Society of London.

Johnson, Rob. 2005. A Region in Turmoil: South Asian Conflicts Since 1947. London: Reaktion Books Ltd.

Jones, Nikoleta, Costas M. Sophoulis, Theodoros Iosifides, and Iosif Botetzagias. 2009. "The Infulence of Social Capital on Environmental Policy Instruments." Environmental Politics 18:595-611.

Kamaladasa, Badra. 2008. "Issues and challenges in river management due to excessive sand mining." in 11th International Riversymposium. Brisbane, Australia www.riversymposium.com/index.php?element=KAMALADASA (Accessed July 2, 2010).

Kondolf, G. 1997. "Hungry Water: Effects of Dams and Gravel Mining on River Channels." Environmental management. 21:533.

Ostrom, Elinor. 2009. "A General Framework for Analyzing Sustainability of SocialEcological Systems." Science 325:419-422.

------. 2010. "The Challenge of Self-Governance in Complex Contemporary Environments." Journal of Speculative Philosophy 24(4):316-332.

Padmalal, D., K. Maya, S. Sreebha, and R. Sreeja. 2008. "Environmental effects of river 102 
sand mining: a case from the river catchments of Vembanad lake, Southwest coast of India." Environmental Geology 54:879-889.

Pretty, Jules, and Hugh Ward. 2001. "Social Capital and the Environment." World development. 29:209.

Sri Lanka Water Partnership. n.d. "Effective Governance as Means to Reducing Corruption in River Sand Mining (RSM): Information Sheet 1.” http://www.lankajalani.org/ (Accessed July 1, 2010).

Sri Lanka Water Partnership. n.d. "Social and Livelihood Impacts of Unregulated and Illicit River Sand Mining (RSM): Information Sheet 5.” http://www.lankajalani.org/ (Accessed July 1, 2010).

Steenbergen, Frank van, and Albert Tuinho. 2009. Managing the Water Buffer: For Development and Climate Change Adaptation: Groundwater Recharge, Retention, Reuse and Rainwater Storage. UNESCO.

Vaillancourt, Jean-Guy. 2010. "From Environmental Sociology to Global Ecosociology: The Dunlap-Buttel Debates.” Pp. 48-62 in The International Handbook of Environmental Sociology, edited by Michael R. Redclift and Graham Woodgate. Cheltenham, UK: Edward Elgar Publishing Limited.

Wong, Josephine, and Maurice Poon. 2010. "Bringing Translation Out of the Shadows: Translation as an Issue of Methodological Significance in Cross-Cultural Qualitative Research.” Journal of Transcultural Nursing 21:151-158. 


\section{APPENDIX: INTERVIEW GUIDE}

\section{Demographics}

Time / Date / Area / Description of home / Translator / People present during interview Age: Gender: Description:

1. Are you married?

a. Do you have any children? (How many?)

2. How many people live in your home?

3. Do you engage in any economic activities?

a. What are they? How long have you been earning an income?

4. What are the main sources of income for your family?

5. How long have you lived in this village?

$\underline{\text { Water }}$

6. Do you ever get water directly from the river? If yes, for what reasons?

7. When your household needs water, where do you go to get it?

a. Are there different water sources for different uses?

b. In your household, whose job is getting water?

c. How much time each day is spent getting water?

d. Do you use the river for washing? (For what \& how often?)

8. Are there any water problems that you face?

a. Can you tell me about them?

b. Have you ever felt there was not enough water?

c. What about too much water?

9. Is the water you get clean enough to drink?

a. Do you have to treat the water before drinking it?

b. Has anyone in your home ever gotten sick from the water?

c. Do you ever have a problem with too much salt in the water?

10. Do you worry about the quality of your water getting worse?

11. Have you noticed changes in the river over time?

\section{Sand Mining}

12. What, if anything, do you know about sand mining?

13. Are you or anyone in your home involved in sand mining?

a. What is your role? What does it involve?

14. If no one were allowed to sand mine anymore, what would happen for your family?

15. Would you be willing to change to an alternative livelihood? (Or encourage a family member to change livelihoods)

a. Why do you feel that way?

b. Have you always felt this way? What changed?

16. Have you (or family member) had any health problems because of sand mining?

17. Do you think that sand mining has an effect on this environment?

a. If yes, what kind of effect? 
b. What about water level or quality?

18. What happened that made you think these things about sand mining?

19. What are the other options to sand mining in this community?

a. Who can do these things? Men? Women? Both?

20. (If they haven't said) Has your overall view of sand mining changed at all?

\section{Environment \& the Community}

21. Can you tell me about what kind of relationships you have with your neighbors?

a. Do you feel connected to your neighbors?

22. Does your family fish? (Have there been changes in the quantity or quality?)

23. Does your family grow food for themselves? (Have there been any changes in this?)

24. Do you feel the health/well-being of your family depends on having a good/healthy environment?

25. If you changed your daily activities because you were told it was better for the environment, would you expect others in the community to do the same?

26. Do you ever worry that people's actions can be harmful to the environment?

a. What actions are you thinking about? Why? Or why not?

b. Do you worry the way you make money can be harmful? What do you do about it?

27. Do people ever fight or argue about water? (If yes, can you tell me about it?)

a. What about the environment in general?

28. In this community, are there any rules about how people should use the environment?

29. If someone took too much water or did something that wasn't good for the water, what would people think?

a. Is this something people talk about?

b. If you knew someone was doing something that was harmful to the environment of this community, what would you do?

30. Do you trust that your neighbors will not do anything they know to be harmful to the community water source?

31. Not thinking about work: how willing are you to change your daily routine for the sake of the environment?

a. If yes, why do you feel this is important?

b. What if it cost you money to make these changes? (More time?)

32. In general, are you concerned for the environment in your community?

a. What about in the future (for your children)?

33. Do people ever talk about sand mining in general?

a. What kinds of things do they say?

34. Do people ever talk about water or the environment in this community?

a. What kinds of things are talked about?

b. Who is involved in these conversations? Men, women, both?

c. If no, do you think this would be helpful? Why?

d. If there was a group like this would you participate?

35. If there is a problem in your community, how do people deal with it? 
36. Do you feel as though you can trust the government to step in and stop people from doing things that may be harmful to the environment you depend on?

a. Why or why not?

37. Do you think that men and women have different views of the environment?

38. Do men and women in this village usually have different activities that they are expected to do? (Can you tell me about that?)

39. Who owns the Maha Oya?

40. Are you aware of what EFL is doing in this community?

a. If yes, can you tell me a little bit about it?

b. Have your views of sand mining or the environment changed because of EFL?

41. Is there anything else you would like to tell me about this that I didn't ask?

42. Is there anything you would like to ask me? 